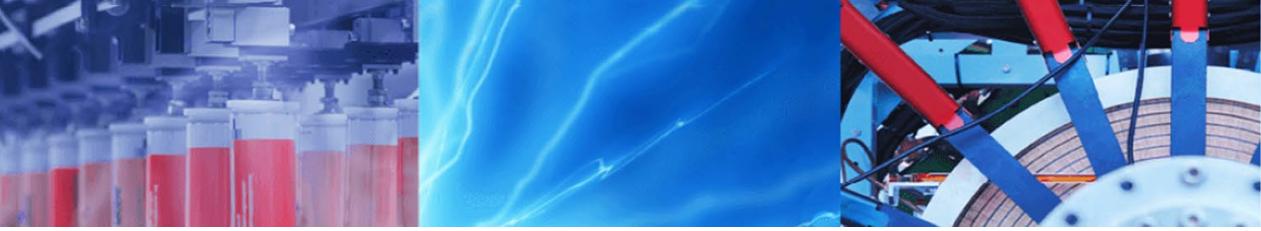

Research Article

\title{
Microrecycling of the metal-polymer-laminated packaging materials via thermal disengagement technology
}

\author{
Abdullah Al Mahmood ${ }^{1} \cdot$ Rumana Hossain $^{1}$ (D) $\cdot$ Veena Sahajwalla ${ }^{1}$
}

(c) Springer Nature Switzerland AG 2019

\begin{abstract}
Polymer-laminated metals are widely used in the packaging industries due to their flexibility of applications, superior properties, and relatively lower cost. Despite the advantages accomplished by the polymer-metal multilayer packaging materials, the recycling is a very difficult task due to the complexities of multimaterial intrinsic behaviors during the processing of cast-off materials. This study represents an innovative and sustainable way of recycling polymerlaminated aluminum packaging (PLAP) materials (postconsumer food packaging) into high-quality aluminum and a potential source of high-energy hydrocarbon gases and particulate carbon coproducts. Both sides of the aluminum foil of the packaging were laminated by two different polymers (polyethylene terephthalate, and polypropylene). Volatiles from the PLAP materials were eliminated by the thermal disengagement technology at $400-650^{\circ} \mathrm{C}(5-30 \mathrm{~min})$ with and without an inert gas supply. The volatiles evaporated from the PLAP materials were about $32 \%$, and the rest $68 \%$ were aluminum ( $65 \%)$ and carbon ( $3 \%)$ from the decomposition of the polymers. The oxidation behavior of the surface of the recycled aluminum was studied by XRD, XPS, and elementary mapping, and a nanoscale oxidized surface was found in both inert and air atmospheric TD. The purity of the aluminum was measured above $98 \%$ by two different methods (LIBS and ICP-MS). The gaseous products released in TD were detected as high energy-carrying hydrocarbon, $\mathrm{CO}_{2}, \mathrm{CO}$, $\mathrm{H}_{2}, \mathrm{H}_{2} \mathrm{O}$, and few other gases observed by real-time monitoring. The clean gases released in TD might be utilized upon reforming into $\mathrm{CH}_{4}$ or $\mathrm{H}_{2}$ by further processing or as it turns out might be utilized as a source of heat energy for other applications. Carbon found from the decomposition of the hydrocarbons can be another useful element of this study. This recycling process offers an economically and environmentally feasible recycling strategy for a complex multilayer polymer-metal packaging waste.
\end{abstract}

Keywords Polymer-laminated aluminum · Thermal disengagement technology · Microrecycling · Aluminum recycling

\section{Introduction}

Aluminum has a versatile application in packaging from food and beverage to medicines, lids, capsules, wraps, foils, trays, aerosol, and liquid containers, and other packs and cartoons. Aluminum packaging offers excellent physical and chemical properties including improved corrosion resistance, impermeability to ultraviolet rays, light, oxygen, water vapor, oils, and microorganisms [1]. In the case of sensitive products packaging, aluminum is nontainting, nontoxic, hygienic and retains the flavor and freshness of the products by protecting them from the external influences [2]. Moreover, the recycling of aluminum is easier because it only consumes $5 \%$ of energy and emits only $5 \%$ of greenhouse gases compared to the production of primary aluminum [3]. Though the lightweight, flexibility, and other chemical and physical properties of aluminum are suitable for packaging, the mechanical strength is not enough for thinner aluminum foil or sheet.

\footnotetext{
$\triangle$ Abdullah Al Mahmood, m.almahmood@student.unsw.edu.au; $₫$ Rumana Hossain, r.hossain@unsw.edu.au | ${ }^{1}$ Centre for Sustainable Materials Research and Technology (SMaRT), University of New South Wales (UNSW), Sydney, NSW 2052, Australia.
}

SN Applied Sciences (2019) 1:1106 | https://doi.org/10.1007/s42452-019-1099-7 
Polymer lamination on the aluminum can provide better protection to permeation of water vapor, light, gas, and ultraviolet rays, as well as improved flexibility for the packaging of sophisticated products which is difficult to find from a single metallic packaging system. Polymer lamination on the metal could be favorable for having superior mechanical strength, though it could be slightly badly arranged in connection with a few other properties, for example, permeability and transparency $[4,5]$. Sometimes, the single-layer polymer film cannot serve the appropriate purpose of lamination; thus, the industries need to develop multilayer film by co-extrusion or lamination techniques. These physical procedures can combine numerous polymers with superior physical, chemical, and mechanical properties $[6,7]$.

Regardless of the advantages accomplished by utilizing the multilayer films, the reusing and recycling of such sort of material are extremely troublesome. The grouping and separation procedures of these multilayer films are hard undertaking because of the polymer likeness. Extrusion recycling of the multilayer polymer films containing incompatible polymer for extrusion is very difficult [8-10]. For example, polyethylene terephthalate (PET) requires a higher temperature for extrusion compared to the other types of polymers, such as polypropylene (PP) and polyethylene ( $\mathrm{PE}$ ). Multilayer polymer-aluminum packaging materials may find difficulties in reshaping and reusing all the associated materials due to their inherent variations in the properties at different conditions. Nevertheless, the heating value of polymer-laminated aluminum packaging (PLAP) materials could be higher than that of biomass because the polymers are mainly composed of carbon and hydrogen $[11,12]$. The purpose of this study is to convert the polymers-laminated aluminum packaging materials into the form of useful solid material and a form of energy by avoiding the integrated complexities of the other recycling processes.

Several mechanical and chemical processes have been practiced for the separation of polymers and recovering the metallic substrate from the polymer-laminated metallic packaging materials [13]. The most useful chemical processes for depolymerization are hydrolysis, glycolysis, and alcoholysis where the depolymerization happens in acidic, basic, or alcoholic solvents [14-18]. But in these processes, the loss of metallic parts from the packaging cannot be controlled. Some other technologies like gasification, molten-salt technology, and pyrolysis with oxygen-free activity could isolate important metals or balance out the substantial metals in waste materials treatment processes in the temperature range from 600 to $800^{\circ} \mathrm{C}$ [19-22].

Metal recovery and polymer removal from the polymer-laminated metal packaging (PLMP) significantly depend on the thermal disengagement atmospheres and the processing temperatures. In the oxygenenriched atmosphere, a certain fraction of aluminum will react with atmospheric oxygen and an oxide layer will form on the surface of the aluminum [23]. An exothermic reaction happens while the aluminum reacts with oxygen as shown in Eq. 1 (molar enthalpy for the oxidation $1675.7 \mathrm{~kJ} / \mathrm{mol}\left[\Delta H_{298 \mathrm{~K}}^{0}\right]$ [24]:

$4 \mathrm{Al}+3 \mathrm{O}_{2}=2 \mathrm{Al}_{2} \mathrm{O}_{3}$

On the other hand, to recover aluminum from the polymer-laminated packaging without significant oxidation an oxygen-free inert atmosphere is an important condition where minimization of oxygen can be maintained by the continuous supply of inert gas. Limited works have been performed on the recovery of postconsumer polymer-laminated metallic packaging due to the difficulties in separation of polymers from the metallic substrates.

This work introduces a sustainable way of microrecycling polymer-laminated aluminum packaging (PLAP) material by thermal disengagement technology (TDT) in an inert and air atmospheric conditions. Microrecycling discovers the effect of transformation temperature and time for the waste material, in this case, polymers and aluminum separately. This technology enables multiple reactions to harness the selective synthesis of pure aluminum without smelting it which has laid the foundations for the development of novel pathways to generate aluminum and cleaner gases from waste, using selective thermal transformations.

The innovative approach of TDT recycles the highquality aluminum comparatively at a lower temperature without smelting. There is no metal loss in this process which makes the process sustainable for the environment and world reserve of aluminum. Aluminum can easily be separated from the carbon coproducts and collected for other applications upon further processing. In the TDT, hydrocarbon gases along with the other gases $\left(\mathrm{CO}, \mathrm{CO}_{2}, \mathrm{H}_{2}\right.$, etc.) produced from the decomposition of the polymers at elevated temperatures help to minimize the oxidation of aluminum as well as they can be reformed into useful fuel gases $\left(\mathrm{CH}_{4}, \mathrm{H}_{2}\right)$. The clean gases in TDT can also be utilized as the source of heat energy for other work cycles. Complete utilization of all the products' outcome from the TDT of waste polymerlaminated aluminum packaging materials makes the recycling technique commercially viable, practically significant, and environmentally friendly. 


\section{Materials and methods}

\subsection{Materials}

Postconsumer coffee pods were collected from local coffee shops and manually shredded into smaller pieces to separate coffee grounds and the packaging materials. Photographs shown in Fig. 1 represent the outside and inside view of the coffee pods.

The coffee pods were made of aluminum foil laminated by different polymers on both sides. The type of laminated polymers was identified by Fourier-transform infrared spectroscopy (Spotlight 400 FTIR, PerkinElmer). The system includes several productivity features and tools, and an incorporated attenuated total reflectance (ATR) system enables the collection of high-resolution data to envision the composition of the materials based on the FTIR spectral data. A most comprehensive search tool Thermo Scientific ${ }^{\text {TM }}$ Spectral ID was used to identify the functional group and the type of the polymers laminated on the aluminum foil.

Thermogravimetric analyzer (TGA, STA8000, Perki$\mathrm{nElmer}$ ) was used to investigate the thermal degradation behavior of polymer-laminated aluminum packaging (PLAP) materials in a nitrogen atmosphere with a continuous supply at $20 \mathrm{ml} / \mathrm{min}$. The samples were heated in the heating chamber of the TGA from atmospheric temperature to $800{ }^{\circ} \mathrm{C}$ at a heating rate of $20^{\circ} \mathrm{C} / \mathrm{min}$. To understand the thermal decomposition kinetics of the coffee pods and analyze the gas evolved during the combustion of the polymers, a Fourier-transform infrared spectroscopy coupled with TGA (TGA-FTIR, Spectrum 100 , PerkinElmer) was used and real-time monitored during the process. The resolution of the infrared spectrum was $4 \mathrm{~cm}^{-1}$, and the range of the absorbance spectrum was $650-4000 \mathrm{~cm}^{-1}$.

\subsection{Summary of the thermal disengagement}

The thermal disengagement of the waste PLAP materials was conducted in a horizontal tube furnace (HTHTF50, $A B B$ ) with a time variation from 5 to 30 min at the temperatures $400-650^{\circ} \mathrm{C}$ as mentioned in Table 1. The inert atmosphere was created by a continuous supply of argon ( $1 \mathrm{~L} /$ $\mathrm{min}$ ) into the heating chamber of the furnace. Also, the thermal degradation behavior of the PLAP materials was analyzed in the same furnace in atmospheric condition at a temperature of $600{ }^{\circ} \mathrm{C}$ without any inert gas supply. To ensure the reproducibility of the experiments, similar process parameters were maintained and the experiments were repeated five times.

To analyze the released gas from the waste PLAP materials during TD, another horizontal tube furnace (HTF7060, Radatherm) was used. The furnace was coupled with an IR gas analyzer (AO2020, Advance Optima, ABB) to monitor
Fig. 1 Coffee pods: a outside (colored), b inside (transparent)
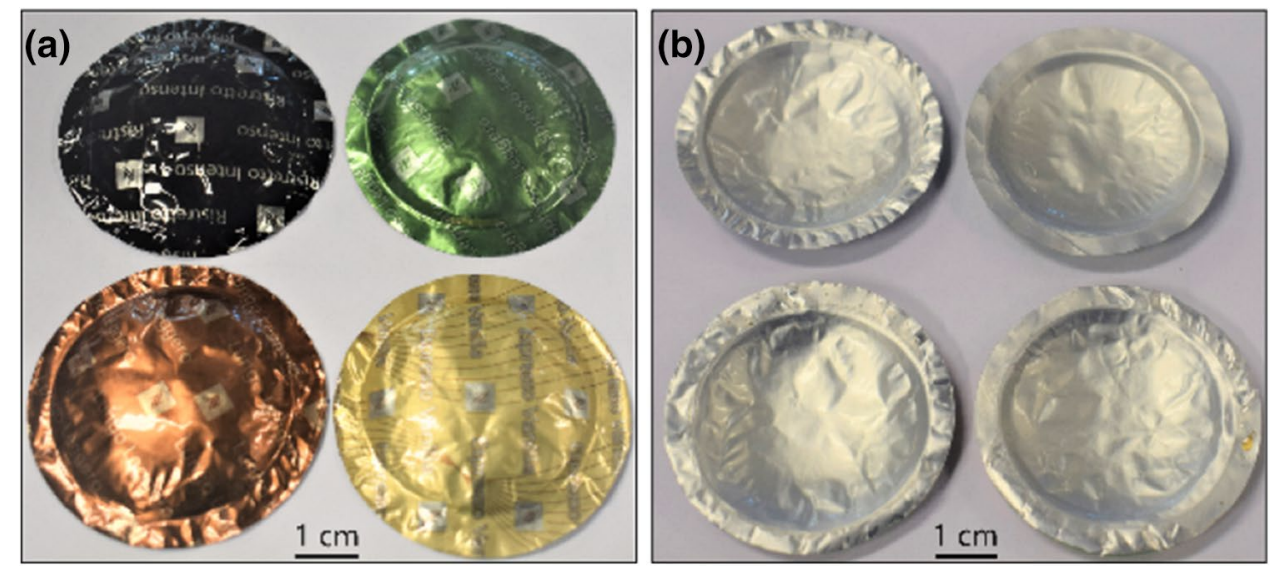

\begin{tabular}{|c|c|c|c|c|c|c|c|}
\hline \multirow[t]{2}{*}{ Time (min) } & \multicolumn{6}{|c|}{ Temperatures (argon atmosphere) and sample ID } & \multirow{2}{*}{$\begin{array}{l}\text { Air } \\
600^{\circ} \mathrm{C}\end{array}$} \\
\hline & $400^{\circ} \mathrm{C}$ & $450^{\circ} \mathrm{C}$ & $500^{\circ} \mathrm{C}$ & $550^{\circ} \mathrm{C}$ & $600^{\circ} \mathrm{C}$ & $650^{\circ} \mathrm{C}$ & \\
\hline 5 & $400 \mathrm{~A}$ & $450 \mathrm{~A}$ & $500 \mathrm{~A}$ & $550 \mathrm{~A}$ & $600 \mathrm{~A}$ & $650 \mathrm{~A}$ & $600 \mathrm{P}$ \\
\hline 10 & $400 \mathrm{~B}$ & $450 \mathrm{~B}$ & $500 \mathrm{~B}$ & $550 \mathrm{~B}$ & 600B & 650B & $600 \mathrm{Q}$ \\
\hline 15 & $400 \mathrm{C}$ & $450 \mathrm{C}$ & $500 \mathrm{C}$ & $550 \mathrm{C}$ & $600 \mathrm{C}$ & $650 \mathrm{C}$ & $600 \mathrm{R}$ \\
\hline 20 & 400D & $450 \mathrm{D}$ & 500D & $550 \mathrm{D}$ & 600D & 650D & 6005 \\
\hline 30 & $400 \mathrm{E}$ & $450 \mathrm{E}$ & $500 \mathrm{E}$ & $550 \mathrm{E}$ & $600 \mathrm{E}$ & $650 \mathrm{E}$ & $600 \mathrm{~T}$ \\
\hline
\end{tabular}

Table 1 Summary of the experimental details with samples ID 
the amount of $\mathrm{CO}, \mathrm{CO}_{2}$, and $\mathrm{CH}_{4}$ gases released from the treatment in the furnace. Emission characteristics of the polymers during the thermal degradation were estimated by the recorded gas emission quantities. After the treatment of PLAP materials at different conditions, the metallic part and the carbonaceous coproducts were collected for further analysis.

\subsection{Characterization techniques}

Aluminum and solid coproducts collected from the thermal disengagement process were characterized by X-ray diffraction system (Empyrean, PANalytical) with cobalt anode. Chemical state and elemental estimation on the surface of the recycled aluminum were observed by Thermo ESCALAB250Xi X-ray photoelectron spectrometer (XPS) which have the depth profile and elemental imaging capability with aluminum Ka X-ray source. The surface morphology and elemental analysis of the aluminum surface and solid coproducts were carried out by field emission electron microscopy (Nano SEM 450, FEI Nova) and energy-dispersive spectroscopy (SDD-EDS, Bruker).

The TEM sample was prepared using a dual-beam FIB (FEl xT Nova NanoLab 200, USA). At first, a strip for the TEM specimen of about 1 micron in width was made by milling two trenches at higher beam current. Then, further mills were performed to narrow down the thickness of the specimen and to make it electron transparent (less than about $100 \mathrm{~nm}$ ). This was performed with a lower beam current around $100 \mathrm{pA}$. Finally, the sample was tilted to cut off the TEM specimen from the rest of the sample. The milled TEM sample was then lifted out with a micromanipulator and placed on a carbon-coated copper grid for TEM observation. The microstructure and elemental composition of the sample were observed using a TEM equipped with a field emission gun (Philips CM 200, the Netherlands).

The percentage of carbon associated with the thermodisengaged PLAP materials was estimated by Leco CS230 carbon and sulfur analyzer by the infrared spectroscopy of the combustion products containing carbon dioxide and carbon monoxide. The quality and composition of the recycled aluminum were analyzed by the laser-induced breakdown spectroscopy (LIBS Analyzer, SciAps, AXT) and inductively coupled plasma mass spectroscopy (ICP-MS) techniques.

\section{Results and discussion}

\subsection{Characterization of waste packaging materials}

To identify the type of the polymers laminated on both sides of the metallic packaging material, Fourier-transform infrared spectroscopy (FTIR) was utilized. The outlook of the coffee pods is different from outside (colored side) and inside (transparent side), and the types of polymers identified on two sides are different. The polymer laminated on the transparent side is polypropylene (PP), and polyethylene terephthalate (PET) is laminated on the colored side of the PLAP materials in this study (shown in Fig. 2a).

To understand the metal-polymer lamination thickness of the coffee pods, the cross section was subjected to the scanning electron microscopy (SEM) with energydispersive spectroscopy (EDS mapping). From Fig. 2a, the thickness of the transparent side, aluminum in the middle, and the colored side was measured by Image J software $(\sim 15.26 \mu \mathrm{m}, \sim 28.55 \mu \mathrm{m}$, and $15.41 \mu \mathrm{m})$ and the mass percentage was calculated based on the density of $\mathrm{PP}=12.11 \%, \mathrm{Al}=67.62 \%$, and $\mathrm{PET}=20.27 \%$ where the density of polypropylene (PP) and polyethylene terephthalate (PET) was taken as $0.95 \mathrm{~g} / \mathrm{cc}[25,26]$ and $1.50 \mathrm{~g} / \mathrm{cc}$ [27]. Figure $2 b$ represents the elemental mapping of the metal-polymer interface of the waste coffee pod, where a trace of silicon was observed between the polymer and aluminum.
Fig. 2 a Cross section of the coffee pod showing the thickness of different sections, $\mathbf{b}$ EDS mapping of the metalpolymer interface

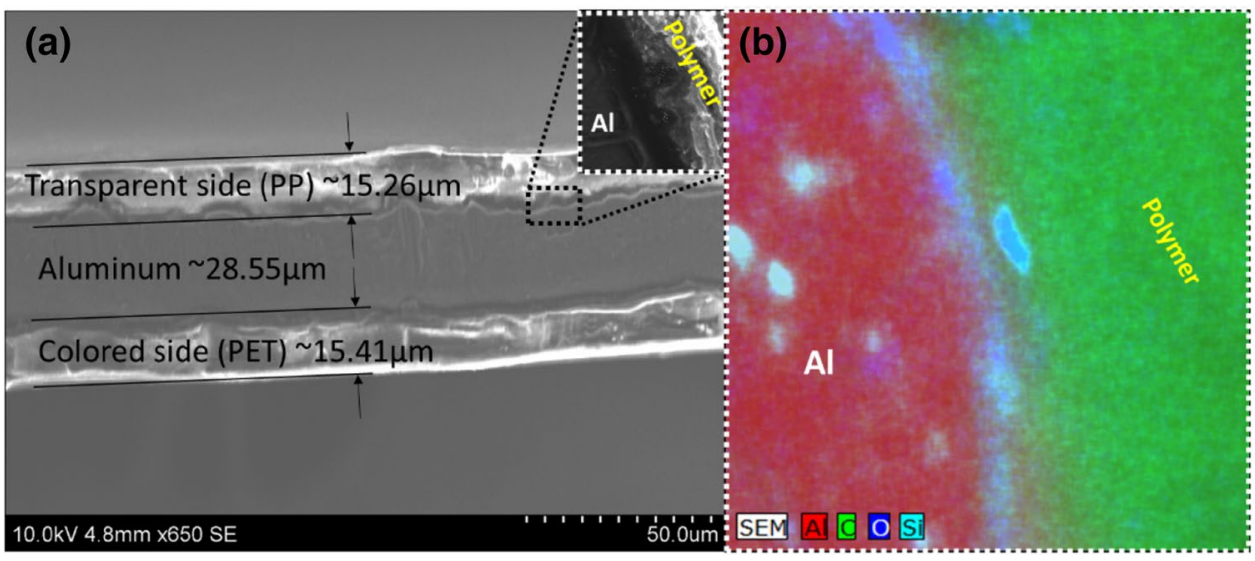




\subsection{Thermal characteristics of the coffee pods}

\subsubsection{Thermogravimetric analysis of PLAP}

Waste polymer-laminated aluminum packaging (PLAP) was subjected to thermal degradation in a thermogravimetric analyzer to understand the behavior of the polymers at elevated temperature, activation energy, frequency factors and complete decomposition factors. The waste packaging was subjected to the heating from atmospheric temperature to $800{ }^{\circ} \mathrm{C}$ at a heating rate of $20^{\circ} \mathrm{C}$ per minute in a nitrogen atmosphere. Figure 3 represents the thermogravimetric analysis (TGA), derivative thermogravimetry (DTG), and heat flow behavior of the polymer-laminated aluminum packaging (PLAP) materials. Thermogravimetric analysis (TGA) represents the double-stage degradation characteristics of PLAP at $300-390{ }^{\circ} \mathrm{C}$ with a slope of the region $-0.01714 \pm 6.9103 \mathrm{e}^{-5}$ and at $390-510^{\circ} \mathrm{C}$ with a slope of the region $-0.28546 \pm 5.8652 \mathrm{e}^{-5}$. The derivative of the TGA curve denoted by DTG clearly represents a single peak at $450{ }^{\circ} \mathrm{C}$ which signifies the ultimate disintegration temperature of the polymers. The PLAP contains two different polymers, polypropylene (PP) and polyethylene terephthalate (PET). Pure polypropylene decomposes at $300-450{ }^{\circ} \mathrm{C}$ with a DTG peak at around $410{ }^{\circ} \mathrm{C}[28$, 29], and polyethylene terephthalate degrades relatively sharply at $400-480^{\circ} \mathrm{C}$ with a DTG peak at around $440{ }^{\circ} \mathrm{C}$ $[30,31]$. It can be assumed that the initial degradation can be attributed by PP and the followed degradation by PET polymers. The weight loss in the whole process was measured as $30.014 \%$. Two endothermic processes can be observed at the temperatures $\sim 450^{\circ} \mathrm{C}$ and $675^{\circ} \mathrm{C}$ in the degradation of PLAP due to the decomposition of polymers (PP and PET) and the melting of aluminum represented by the heat flow characteristic curve.

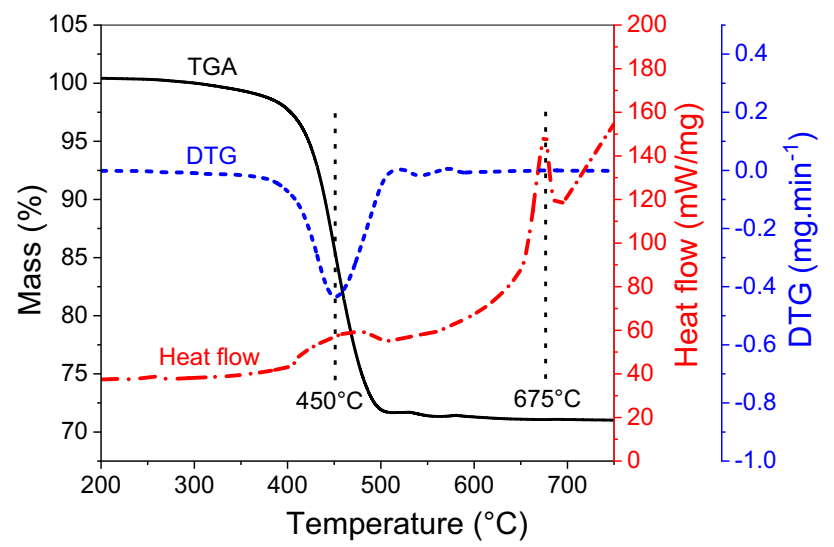

Fig. 3 TGA, DTG, and heat flow characteristics of PLAP

\subsubsection{Thermal degradation kinetics of PLAP}

Kinetic parameters in the thermal degradation of polymerslaminated metallic packaging materials can be correlated with the absolute temperature $\left(T_{a}\right)$ and the heating rate $(a)$ in the nonisothermal analysis [32] and can be written as:

$T_{a}=T_{i}+\alpha t$

where $T_{i}$ is the initial temperature and $t$ is the time. The rate of specific reaction can be written as:

$\frac{\mathrm{d} \beta}{\mathrm{d} t}=q \cdot f(\beta)$

where $\beta$ is the extent of conversion in the range of $0-1$ and it can be written as:

$\beta=\frac{W_{o}-W_{t}}{W_{o}-W_{r}}$

where $W_{o}$ is the initial mass, $W_{t}$ is the instant mass, and $W_{r}$ is the residual mass. The combination of Eqs. 2 and 3 can be written as:

$\frac{\mathrm{d} \beta}{\mathrm{d} T_{a}}=\frac{\mathrm{d} \beta}{\mathrm{d} t} \times \frac{\mathrm{d} t}{\mathrm{~d} T_{a}}=\frac{q f(\beta)}{\alpha}$

or $q=\frac{\left(\mathrm{d} \beta / \mathrm{d} T_{a}\right) \alpha}{f(\beta)}$.

It is considered that the rate $\frac{\mathrm{d} \beta}{\mathrm{d} t}$ depends on the $\beta$ and the factor $q$ depends on the temperature of degradation of polymers in the isothermal process. This dependency can be described by the Arrhenius law:

$q=A \exp \left(\frac{-E}{R T_{a}}\right)$

where $A$ is the pre-exponential factor and $E$ is the activation energy and $R$ is the universal gas constant $[R=8.3145 \mathrm{~J}$ $\mathrm{K}^{-1} \mathrm{~mol}^{-1}$. Combining Eqs. 6 and 7, the following equation can be drawn:

$\frac{\mathrm{d} \beta}{\mathrm{d} T_{a}}=\frac{A}{\alpha} f(\beta) \exp \left(\frac{-E}{R T_{a}}\right)$

For $n$ th-order reaction, the function $f(\beta)$ can be written as:

$f(\beta)=(1-\beta)^{n}$.

Combining Eqs. 8 and 9, the equation for $n$ th-order reaction can be drawn as:

$\frac{\mathrm{d} \beta}{(1-\beta)^{n}}=\frac{A}{\alpha} \exp \left(\frac{-E}{R T_{a}}\right) \mathrm{d} T_{a}$.

Equation 10 can be called a differential method. To find out the kinetic parameters for thermal decomposition of 


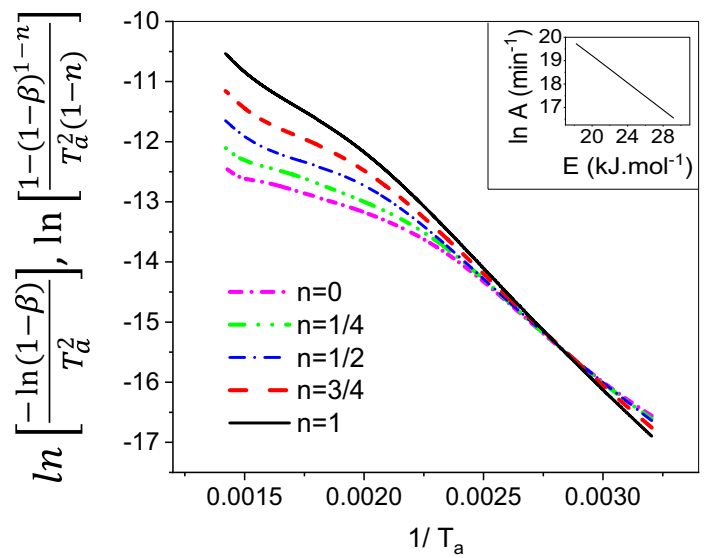

Fig. 4 Coats-Redfern plots for the thermal degradation of PLAP and kinetic compensation effect (inset) of the Coats-Redfern plot

Table 2 Kinetic parameters and fitting data from the TGA analysis of waste packaging estimated by Coats-Redfern method

\begin{tabular}{llllll}
\hline Order & Intercept & Slope & Adj. $R^{2}$ & $E(\mathrm{~kJ} / \mathrm{mol})$ & $\begin{array}{l}\operatorname{In} A \\
\left(\mathrm{~min}^{-1}\right)\end{array}$ \\
\hline$n=1$ & 5.375 & -3512.07 & 0.9909 & 29.201 & 16.544 \\
$n=3 / 4$ & 6.646 & -3048.52 & 0.9833 & 25.346 & 17.656 \\
$n=1 / 2$ & 7.640 & -2689.50 & 0.9739 & 22.361 & 18.532 \\
$n=1 / 4$ & 8.418 & -2411.05 & 0.9622 & 20.046 & 19.203 \\
$n=0$ & 9.046 & -2187.06 & 0.9506 & 18.184 & 19.731 \\
\hline
\end{tabular}

polymers, Coats-Redfern formula [33] can be derived by integrating Eq. 10:

When $n=1, \quad \ln \left[\frac{-\ln (1-\beta)}{T_{a}^{2}}\right]=\ln \left(\frac{A R}{\alpha E}\right)-\frac{E}{R T_{a}}$

And when $n \neq 1, \quad \ln \left[\frac{1-(1-\beta)^{1-n}}{T_{a}^{2}(1-n)}\right]=\ln \left(\frac{A R}{\alpha E}\right)-\frac{E}{R T_{a}}$

Kinetic parameters of the decomposition can be derived from Eqs. 11 and 12. The exponential factor $(A)$ and the activation energy $(E)$ can be calculated from the intercept $\ln \left(\frac{A R}{\alpha E}\right)$ and slope $\left(\frac{-E}{R}\right)$ of the curves obtained by plotting $\ln \left[\frac{-\ln (1-\beta)}{T_{a}^{2}}\right]$ or $\ln \left[\frac{1-(1-\beta)^{1-n}}{T_{a}^{2}(1-n)}\right]$ against $\frac{1}{T_{a}}$ represented in Fig. 4. Table 2 summarizes the fitting data along with the activation energy $(E)$ and pre-exponential factor $(A)$ calculated from the analysis of Coats-Redfern plots. Thus, the underlying mechanism of reaction upon the application of heat energy can be estimated by the kinetic parameters. To initiate the degradation process by reaction mechanism, a threshold energy level must be overcome by the system which is known as activation energy and the frequency of the molecular collisions during the degradation process can be considered as the pre-exponential factor [34]. The rate of devolatilization of the polymers from the PLAP can be estimated by the order of the reaction, $n$ [35]. It can be noted from Table 2 that the value of activation energy increases from 18.184 to $29.201 \mathrm{~kJ} / \mathrm{mol}$ to increase the order of the reaction $(n)$ from 0 to 1 . A simultaneous increment in the slope from -2187.06 to -3512.07 can also be observed for the same change in the reaction order which indicates the minimization of reaction time by increasing the rate of reaction.

The logarithm of pre-exponential factor $(A)$ has a strong relationship with the change in activation energy $(E)$ by means of any circumstances. It can be represented by a linear expression $\ln A=a E+b$, where the constant $a$ is the slope and the constant $b$ is the intercept and the relation between $E$ and $A$ is well known in the literature as "kinetic compensation effect" [36-38]. According to this relationship, a well-distinguished straight line should be resulted by plotting the logarithmic value of the pre-exponential factor against the activation energy. This characteristic relation of $\ln A$ with $E$ also validates the kinetic parameters derived by the Coats-Redfern method [35]. Figure 4 (inset) is the kinetic compensation effect for the degradation of PLAP at a heating rate of $20^{\circ} \mathrm{C} / \mathrm{min}$ obtained from the plotting of $\operatorname{In} A$ against $E$ which is a distinct straight line and signifies the validation of Coats-Redfern model for the analysis of thermal disengagement of PLAP materials.

\subsubsection{FTIR of the released gas by thermal degradation of PLAP}

The volatile gases released from the thermal degradation of polymer-laminated aluminum packaging (PLAP) were simultaneously analyzed by an FTIR coupled with TGA. A 3D spectrum for the analysis of released gases during the whole process of thermogravimetric analysis is shown in Fig. 5a where two horizontal axes represent the time of analysis and the wave number in the range of $450-4000 \mathrm{~cm}^{-1}$ and the vertical axis shows the absorption intensities. The temperature range for the $3 \mathrm{D}$ spectrum is $30-800^{\circ} \mathrm{C}$ at a heating rate of $20^{\circ} \mathrm{C} / \mathrm{min}$. Figure $5 \mathrm{~b}$ represents FTIR spectrums in nine different time intervals for the whole thermal degradation process to find out the ultimate gas release characteristics of PLAP materials in the combustion chamber of TGA. The recorded temperatures for the related spectrums were $140^{\circ} \mathrm{C}, 240^{\circ} \mathrm{C}, 376^{\circ} \mathrm{C}$, $404^{\circ} \mathrm{C}, 440^{\circ} \mathrm{C}, 540^{\circ} \mathrm{C}$, and $740{ }^{\circ} \mathrm{C}$. The maximum intensity of the IR absorption at $404^{\circ} \mathrm{C}$ signifies that the rate of volatiles release was maximum after the heating temperature reached $404{ }^{\circ} \mathrm{C}$ which is well supported with the result observed from TGA analysis shown in Fig. 3. 

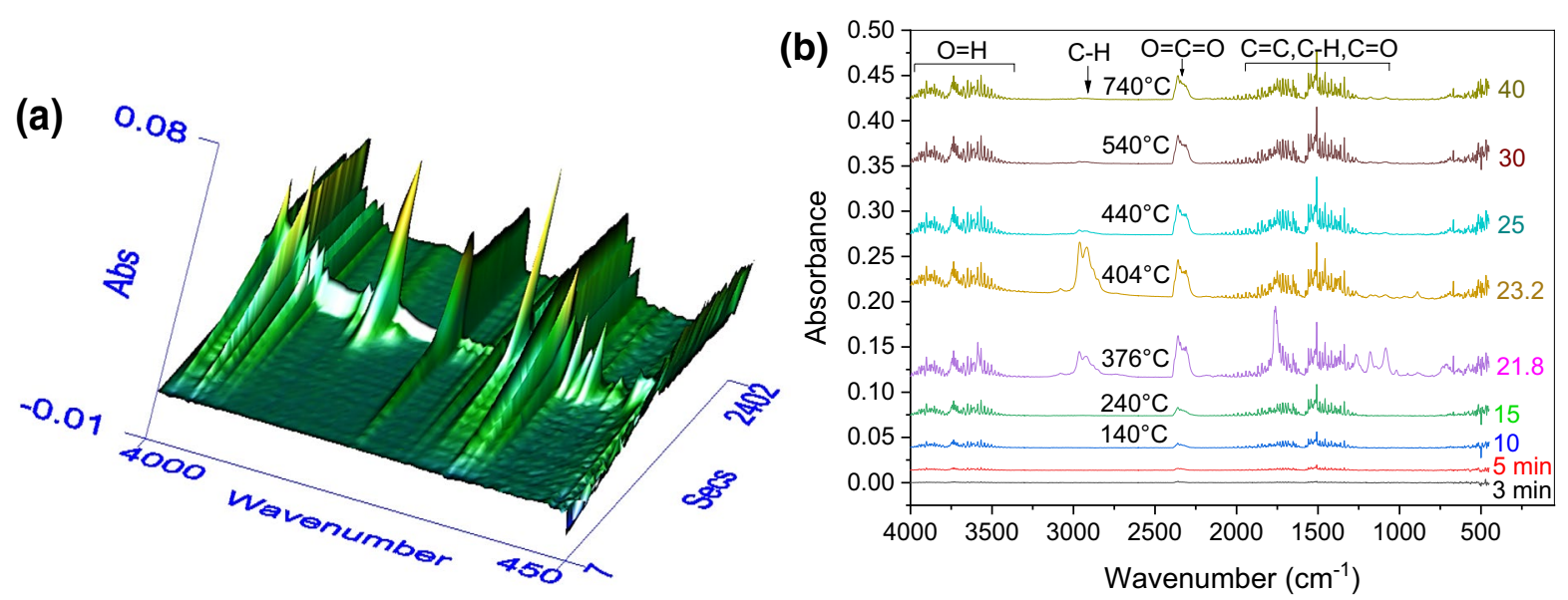

Fig. 5 a Three-dimensional FTIR spectrum of the released gas during the thermal degradation of PLAP and $\mathbf{b}$ comparison of the IR absorbance characteristics at different temperatures during the thermal degradation process

The absorption spectrums in Fig. 5 can be divided into five significant segments $\left(4000-3200 \mathrm{~cm}^{-1}\right.$, $3200-2600 \mathrm{~cm}^{-1}, 2600-2000 \mathrm{~cm}^{-1}, 2000-750 \mathrm{~cm}^{-1}$, and $750-650 \mathrm{~cm}^{-1}$ ) to identify the chemical bonds from the different functional groups. The absorption peaks in the frequency range $3700-3200 \mathrm{~cm}^{-1}$ indicate the free or intermolecular bonded $\mathrm{O}-\mathrm{H}$ stretching functional group [39]. Absorption bands in the range of $3200-2600 \mathrm{~cm}^{-1}$ specify strong, medium and weak $\mathrm{C}-\mathrm{H}$ stretching vibrations mostly in the alkane class [40,41]. A significant behavior can be observed for the peak at $2966 \mathrm{~cm}^{-1}$ with different times and temperatures. There was no peak at the position within $15 \mathrm{~min}$ when the temperature was $240^{\circ} \mathrm{C}$, but when the heating temperature reached $376^{\circ} \mathrm{C}$, a significant peak can be clearly seen which indicates the disintegration of $\mathrm{C}-\mathrm{H}$ bond in the aromatic ring was begun at this temperature and hydrocarbon gases can be released from the degradation of polymers of the PLAP materials. No trace of $\mathrm{C}-\mathrm{H}$ stretching groups can be seen after the heating of $30 \mathrm{~min}$ (the temperature more than $500^{\circ} \mathrm{C}$ ). In the frequency range of $2600-2000 \mathrm{~cm}^{-1}$, a significant peak can be observed at $2357 \mathrm{~cm}^{-1}$ which might be ascribed to the asymmetric $\mathrm{O}=\mathrm{C}=\mathrm{O}$ functional groups of carbon dioxide $\left(\mathrm{CO}_{2}\right)[42]$. In the range of $2000-750 \mathrm{~cm}^{-1}$, there are several minor peaks at $1508 \mathrm{~cm}^{-1}, 1458 \mathrm{~cm}^{-1}, 1362 \mathrm{~cm}^{-1}, 1268 \mathrm{~cm}^{-1}$, $1183 \mathrm{~cm}^{-1}, 1091 \mathrm{~cm}^{-1}, 1024 \mathrm{~cm}^{-1}$, and $895 \mathrm{~cm}^{-1}$ including a major peak at $1760 \mathrm{~cm}^{-1}$ which can be attributed to the $\mathrm{C}=\mathrm{O}$ stretching functional group with a strong appearance [39]. Other weak absorbance peaks in the range $2000-750 \mathrm{~cm}^{-1}$ can be assigned to the $C=C$ stretching functional group in alkene, amine, and ketone [43] and $\mathrm{C}-\mathrm{H}$ bending vibrations in the methylene group along the symmetry axis of carbon $[42,44-47]$.
A series of smaller peaks along with a characteristic peak at $671 \mathrm{~cm}^{-1}$ can be seen throughout the process which can be ascribed to the out-of-plane bending vibration of $\mathrm{C}-\mathrm{H}$ bonds with a dipole moment of transition along the symmetry axis of $\mathrm{C} 4$ in the aromatic hydrocarbons $[44,47]$. In summary, from the decomposition of PLAP materials in TGA-FTIR system, dominant peaks are identified for hydrocarbon gases in alkane $\left(2966 \mathrm{~cm}^{-1}\right)$ and aromatic groups $\left(750-650 \mathrm{~cm}^{-1}\right)$, carbon dioxide $\left(2357 \mathrm{~cm}^{-1}\right)$ and carbon monoxide $\left(1760 \mathrm{~cm}^{-1}\right)$ gases and slight water vapor. Hydrocarbon gases were released due to the decomposition of PP and PET polymers [48-50], and in the absence of oxygen, some $\mathrm{CO}_{x}\left(\mathrm{CO}, \mathrm{CO}_{2}\right)$ gases and water vapors were released from the pyrolytic decomposition of PLAP [48-50].

\subsubsection{Thermal disengagement technology (TDT) of PLAP}

Thermal disengagement (TD) of polymer-laminated aluminum packaging (PLAP) materials was carried out in a horizontal tube furnace with a continuous supply of argon (1 L/ $\mathrm{min}$ ) to ensure the inert atmosphere in the heating chamber of the furnace system. Figure 6 a represents the percentages of volatiles released during the TD in the controlled environment created by the continuous flow of argon gas inside the combustion chamber throughout the pyrolytic processing of the PLAP materials in the range of temperatures from 400 to $650^{\circ} \mathrm{C}$. To find out the optimum temperature and holding time for the complete decomposition of the polymers from the PLAP materials, the pyrolytic treatments were carried out for 5,10,15,20, and $30 \mathrm{~min}$. The processes were repeated five consecutive times with a variation in the weight of the feed materials to confirm the reproducibility of the processing techniques. Volatile components from the polymers can be 
(a)

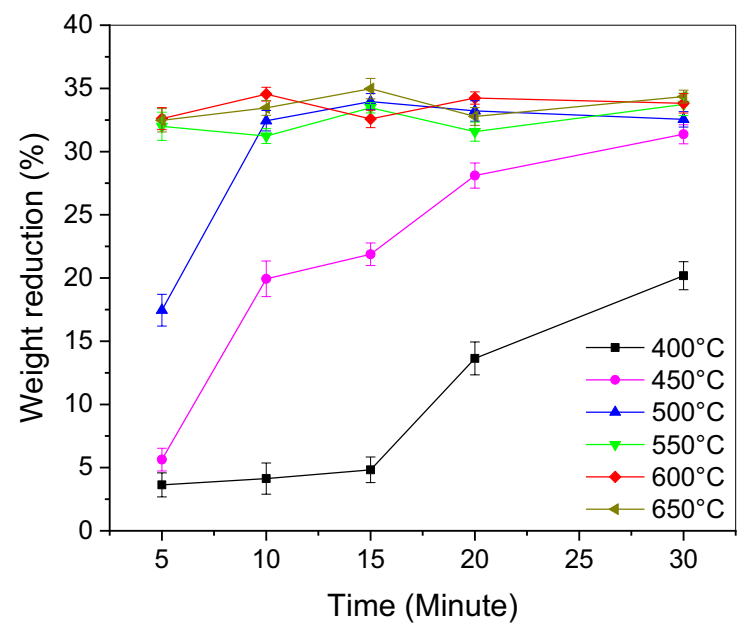

(b)

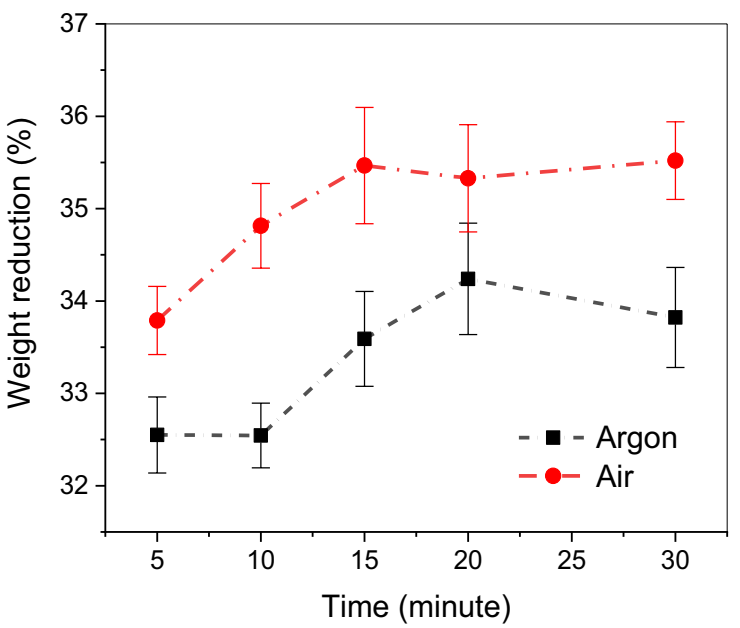

Fig. 6 a Comparison of weight loss in an inert (argon) atmosphere at different temperatures and $\mathbf{b}$ comparison of weight loss during thermal disengagement at $600^{\circ} \mathrm{C}$ in argon and air atmosphere

released after the heating temperature of $300^{\circ} \mathrm{C}$ (evidence from the FTIR gas analysis and TGA analysis). But there are a time and temperature when the residues of the polymers are removed quite easily from the pyrolyzed PLAP compounds. Considering the volatile-releasing, residual removal, melting of the aluminum and the quality of the products, it can be observed that the temperature $600^{\circ} \mathrm{C}$ can be the suitable temperature for the TD of PLAP materials. So, PLAP materials were subjected to the thermal disengagement at $600^{\circ} \mathrm{C}$ in the air atmosphere without the supply of any other gases into the furnace chamber to observe the volatiles removal characteristics of PLAP in air atmosphere. Figure $6 \mathrm{~b}$ represents a comparative characteristic of the reduction in the weight of PLAP materials in argon and air atmosphere at $600{ }^{\circ} \mathrm{C}$ in the time period of 5-30 min. It can be clearly observed that the reduction in weight in case of air atmosphere is always a bit higher, and it can be explained as the polymers can be oxidized upon exposure to the oxygencontaining atmosphere [51].

Polymers degradation usually happens by the abstraction of hydrogen or carbon-carbon bond scission upon the influence of heat or light. The polymer degradation starts with the forming of free radicals as follows [52]:

$\mathrm{R}-\mathrm{H} \rightarrow \mathrm{R}+\mathrm{H}^{\prime}$

where $R^{\prime}$ is the free radical of $R$ and $H$ is the free radical of hydrogen. This degradation can be followed by other reaction of free radicals and oxygen molecules which might be present in the atmosphere or in the polymer itself:

$\mathrm{R}+\mathrm{O}_{2} \rightarrow \mathrm{ROO}$ where ROO is the peroxy radical and a hyperoxide $(\mathrm{ROOH})$ can be formed by abstracting hydrogen from another $\mathrm{R}-\mathrm{H}$ polymer chain:

$\mathrm{ROO}^{\circ}+\mathrm{R}-\mathrm{H}^{\prime} \rightarrow \mathrm{R}^{\circ}+\mathrm{ROOH}$

Two different free radicals would be formed by splitting the hyperoxide $(\mathrm{ROOH})$

$\mathrm{ROOH} \rightarrow \mathrm{RO}^{\circ}+\mathrm{OH}$

Free radicals once again can be combined to terminate the degradation process which might increase the crosslink density or molecular weight:

$\mathrm{R}+\mathrm{R} \rightarrow \mathrm{R}-\mathrm{R}$

$\mathrm{R}+\mathrm{OR} \rightarrow \mathrm{ROR}$

$\mathrm{R}^{\prime}+\mathrm{OOR} \rightarrow \mathrm{ROOR}$

Oxygen at its singlet state (electronic state) is very reactive and can cause auto-oxidation on the surface and scission of the double-bond carbon into an intermediate dioxetane [52].

${ }^{C=C} \backslash+O_{2} \rightarrow-C-C-C$

The bond between oxygens is a weak bond and dissociates upon heating which may participate to form free radicals. Those free radicals always have a great influence on the composition of the residual pyrolytic combustion products. Figure 7 represents the comparative appearance of the thermo-disengaged PLAP materials in air and argon atmosphere at $600^{\circ} \mathrm{C}$ temperature for $5,10,15,20$, and $30 \min (600 \mathrm{P}, 600 \mathrm{Q}, 600 \mathrm{R}, 600 \mathrm{~S}, 600 \mathrm{~T}, 600 \mathrm{~A}, 600 \mathrm{~B}, 600 \mathrm{C}$, 
Fig. 7 Comparison of thermodisengaged aluminum surfaces (at $600^{\circ} \mathrm{C}$ ) $\mathbf{a}-\mathbf{e}$ in air and $\mathbf{f}-\mathbf{j}$ in argon

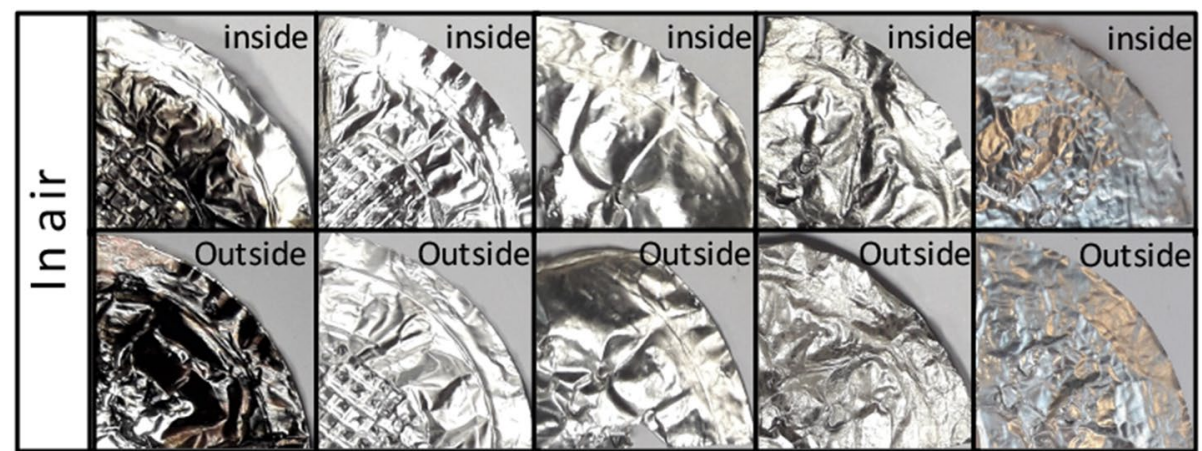

(a) $5 \mathrm{~min}$

(b) $10 \mathrm{~min}$ (c) $15 \mathrm{~min}$ (d) $20 \mathrm{~min}$ (e) $30 \mathrm{~min}$

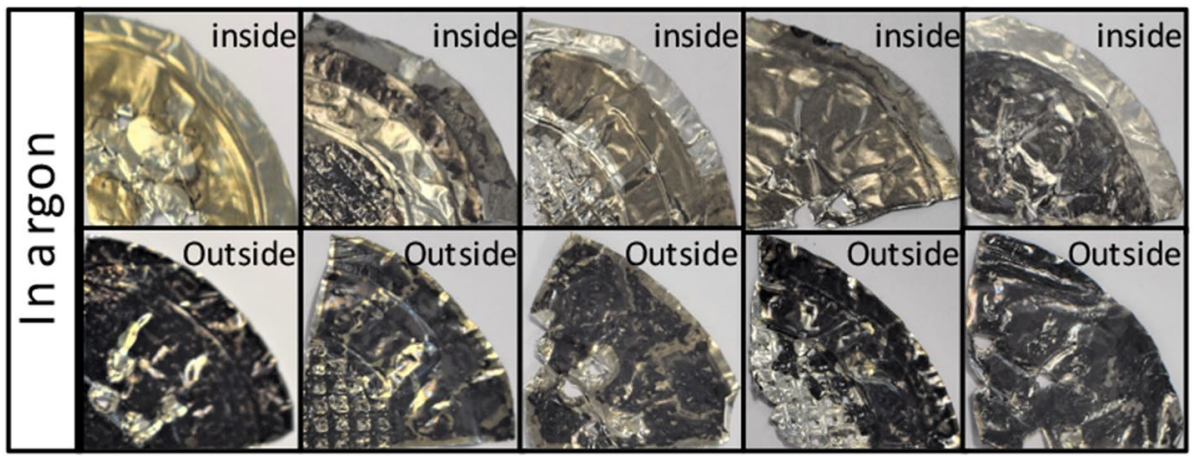

(f) $5 \mathrm{~min} \quad$ (g) $10 \mathrm{~min}$ (h) $15 \mathrm{~min}$ (i) $20 \mathrm{~min} \quad$ (j) $30 \mathrm{~min}$
$600 \mathrm{D}$, and $600 \mathrm{E})$. From the images, a change of colors from the dark to shiny with the increment in time for air media and from light yellow to a deep black for the argon media can be observed. Within 10 min of thermal disengagement in the air, a clean shiny surface of aluminum can be observed (shown in Fig. 7b). A thin layer of $\mathrm{Al}_{2} \mathrm{O}_{3}$ can form on the surface of aluminum $(600 \mathrm{R}, 600 \mathrm{~S}$, and $600 \mathrm{~T})$ in case of heating time more than $10 \mathrm{~min}$ as they are exposed to the atmospheric oxygen after a complete disengagement of the polymers from the metal. In air, polymers react with atmospheric oxygen and eliminate different gases ( $\mathrm{CO}$, $\mathrm{CO}_{2}, \mathrm{H}_{2} \mathrm{O}, \mathrm{H}_{2}$, etc.) which can cause more reduction in polymers (shown in Fig. 6b) in comparison with the thermal disengagement carried out in argon, where some black char/coproduct is left over on the surface of aluminum due to the incomplete combustion of the polymers in the absence of oxygen. Basically, the residue formation from the polymers can commonly happen after the formation of a structure called polyphenylene and the polymers having the aromatic rings exhibit additional tendency to form this structure [52]. In PALP, there are two polymers: PP is on inside and PET on the outside, where the structure of PET polymers contains aromatic rings. For this reason, PET on the outside of the PLAP always leaves more black residues than the inside with PP laminates. The polymers will leave more residual materials (five ring cycles, hydrogen, carbons, residual groups from the original polymers, etc.) if there is a limited flow or availability of exhaust carrying gases. A complicated carbonization reaction takes place as a sequence of the complete decomposition of the polymers [53].

\subsubsection{Emission during the TD}

Off-gas during the polymer decomposition by heat in a controlled atmosphere was simultaneously analyzed with the TD of PLAP materials. Combustion of polymers at the temperatures $500-800^{\circ} \mathrm{C}$ can produce carbon monoxide, carbon dioxide, water vapor, and a series of saturated and unsaturated hydrocarbons like methane, ethylene, methanol, benzene, formaldehyde, acetone, ethanol, styrene, toluene, terephthalic acid, xylene, naphthalene, biphenyl, ethylbenzene, and phenol [54]. In this study, the infrared gas analyzer coupled with the furnace was capable of measuring the concentration of $\mathrm{CO}_{2}, \mathrm{CO}$, and $\mathrm{CH}_{4}$ from the gas evolved during the thermal disengagement of PLAP materials. Figure 8 represents the gas evolution behavior of PLAP materials during the thermal disengagement at $550{ }^{\circ} \mathrm{C}, 600{ }^{\circ} \mathrm{C}$, and $650{ }^{\circ} \mathrm{C}$. It can be observed that the decomposition of PLAP materials finishes within $700 \mathrm{~s}$ where it is reduced to $650 \mathrm{~s}$ for the higher temperature $\left(650^{\circ} \mathrm{C}\right)$. From the observations, it can be summarized that the concentrations of $\mathrm{CO}$ and $\mathrm{CO}_{2}$ gases were increased with the increase in temperatures from 550 to 600 to 


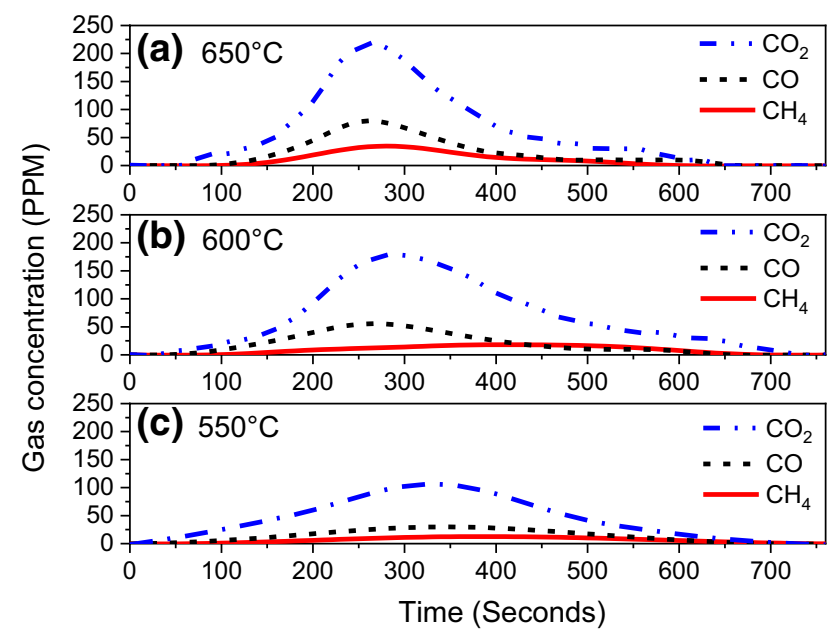

Fig. $8 \mathrm{CO}_{2}, \mathrm{CO}$, and $\mathrm{CH}_{4}$ gas emission characteristics of PLAP materials at a $6500^{\circ} \mathrm{C}, \mathbf{b} 600^{\circ} \mathrm{C}$, and $\mathbf{c} 550^{\circ} \mathrm{C}$

$650^{\circ} \mathrm{C}$ (CO: $1030 \mathrm{ppm}, 1420 \mathrm{ppm}$, and $1580 \mathrm{ppm}$, respectively, and $\mathrm{CO}_{2}: 3380 \mathrm{ppm}, 4490 \mathrm{ppm}$, and $5020 \mathrm{ppm}$, respectively), where the concentration of $\mathrm{CH}_{4}$ tends to decrease after the temperature was increased from 600 to $650^{\circ} \mathrm{C}\left(\mathrm{CH}_{4}: 470 \mathrm{ppm}, 740 \mathrm{ppm}\right.$, and $\left.650 \mathrm{ppm}\right)$. This could be ascribed by the thermal cracking of hydrocarbon gases and reforming into $\mathrm{CO}_{\mathrm{x}}$ gases under the high-temperature condition as follows [55]:

$\mathrm{CH}_{4}+\mathrm{H}_{2} \mathrm{O} \rightarrow \mathrm{H}_{2}+\mathrm{CO}$

$\mathrm{CH}_{4}+\mathrm{CO}_{2} \rightarrow \mathrm{H}_{2}+\mathrm{CO}$

Hydrocarbon gases initially produced by the scission decomposition and thermal cracking of the polymers [56] later on reacted with the steam produced by the decomposition of polymers at lower temperature and $\mathrm{CO}_{2}$ to reform into hydrogen and carbon monoxide gases, and thus the concentration of the $\mathrm{CH}_{4}$ gas reduced at the higher temperature which is in a good agreement with the literature $[55,57]$.

\subsection{Surface analysis of the thermo-disengaged aluminum}

\subsubsection{FTIR analysis}

Figure 9 represents the Fourier-transform infrared spectroscopy (FTIR) analysis of the inside and outside of the PLAP materials thermo-disengaged at $500^{\circ} \mathrm{C}, 550^{\circ} \mathrm{C}$, and $600^{\circ} \mathrm{C}$ for $5-30 \mathrm{~min}$ in an inert atmosphere created by argon flow. In general, prominent peaks can be identified in three specified segments for all the spectrums (3135-2780 $\mathrm{cm}^{-1}, 1700-1400 \mathrm{~cm}^{-1}$, and $1000-650 \mathrm{~cm}^{-1}$ ). It is obvious that there was a significant existence of the residues from the thermo-degraded polymer laminates on both sides of aluminum. The scission decomposition of the polymeric bonds was accelerated at elevated temperature with the increment in thermal disengagement time. As a result, a momentous change in the peak intensities can be observed with the time and temperatures. The residual peaks from the absorption band at $\sim 3044 \mathrm{~cm}^{-1}$ instigated by $\mathrm{C}-\mathrm{H}$ stretching vibration with the medium appearance in the alkene compound class can be assigned to $\mathrm{CH}, \mathrm{CH}_{2}$, and $\mathrm{CH}_{3}$ groups with the $\mathrm{sp}^{2}$ and $\mathrm{sp}^{3}$ configurations where below $3000 \mathrm{~cm}^{-1}$ wave numbers, the smaller peaks correspond to the stretching (asymmetrical) in $\mathrm{CH}_{2}$ with the $\mathrm{sp}^{3}$ aliphatic configuration [58]. The absorption band at $\sim 1605 \mathrm{~cm}^{-1}$ can be ascribed to the medium cyclic aromatic hydrocarbon group (alkene) with the ring vibration of carbon linear bonds $(C=C)[58,59]$. The intensity of this peak reduces with the time of thermal disengagement and the surrounding temperatures which signifies that the complete disintegration of polymeric bonds makes the separation of residues from the aluminum surface easier at higher treatment temperatures for a longer time. A prominent peak at $\sim 940 \mathrm{~cm}^{-1}$ could be visible at the same condition which might be assigned to the $\mathrm{Al}-\mathrm{O}$ group (in $\mathrm{Al}_{2} \mathrm{O}_{3}$ form) [60-62]. At the lower temperatures and time, there are no visible peaks at $\sim 940 \mathrm{~cm}^{-1}$, but with the increment in exposure time and temperatures, the peaks become protuberant, which might be caused by diminutive surface oxidation (oxygen can also present in the argon as an impurity) after the disengagement of aluminum with the polymers [62]. Though the ATR-FTIR system can collect the data in the range from 650 to $4000 \mathrm{~cm}^{-1}$, there is no clear evidence to differentiate among the spectrums in the lower region $\left(800-650 \mathrm{~cm}^{-1}\right)$ where there is a probability of existing silicon ( $\mathrm{Si}$ ) in that region [63].

\subsubsection{XRD of the recovered aluminum by TDT}

The crystallographic parameters and elemental details of the thermo-disengaged PLAP materials were characterized by X-ray diffractometry (XRD) depicted in Fig. 10. This figure represents the XRD patterns for the samples treated at $600{ }^{\circ} \mathrm{C}$ for 5,15 , and $30 \mathrm{~min}$ (in argon) and at $600{ }^{\circ} \mathrm{C}$ for $30 \mathrm{~min}$ (in the air) to understand the compositional change and the effect of the thermal disengagement atmosphere on the surface chemistry of the PLAP materials. The behavior of the XRD patterns for all the samples in the range of $18-28^{\circ}$ shows a characteristic deflection which is quite possible due to the existence of polymers on the metallic surface [64-68]. Major component detected by the XRD is aluminum (fcc structure, peaks at $40.6^{\circ}, 45.2^{\circ}, 47.3^{\circ}, 52.5^{\circ}$, $77.6^{\circ}$, and $\left.94.5^{\circ}\right)$, and few other detected components were $\mathrm{SiO}_{2}$ (peaks at $32.2^{\circ}, 42.9^{\circ}, 73.7^{\circ}$, and $83.4^{\circ}$ ) and $\mathrm{Al}_{2} \mathrm{O}_{3}$ (peaks at $29.5^{\circ}, 49.3^{\circ}, 69.1^{\circ}$, and $90.1^{\circ}$ ). It is clear evidence 
(a)

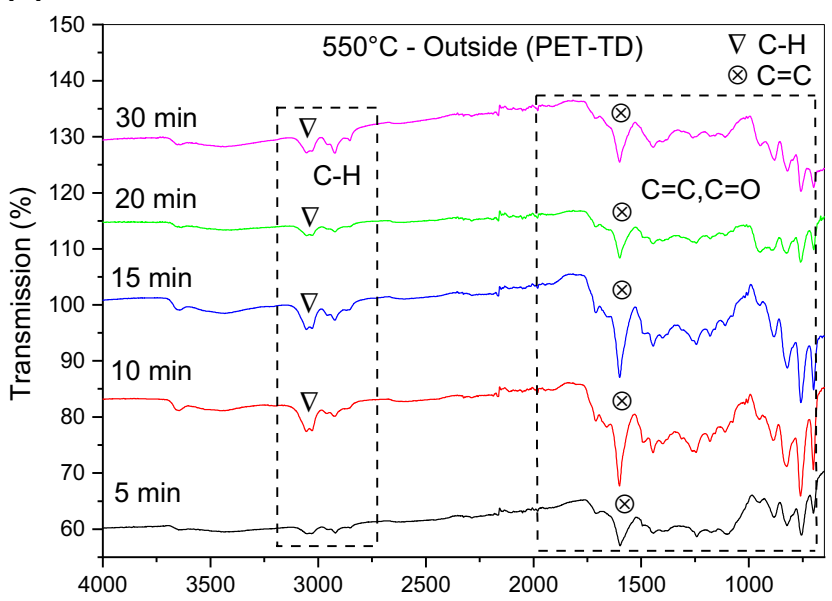

(c)

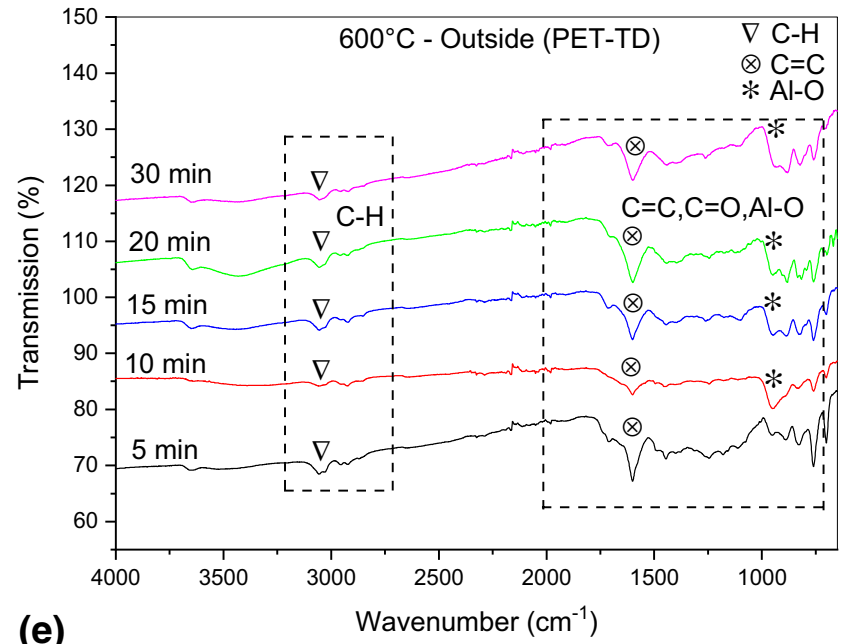

(e)

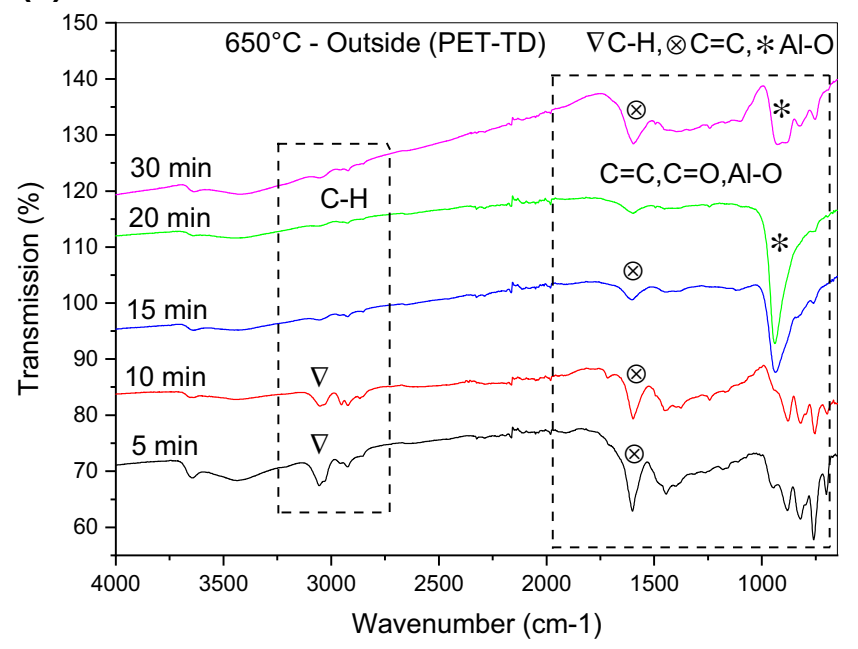

(b)

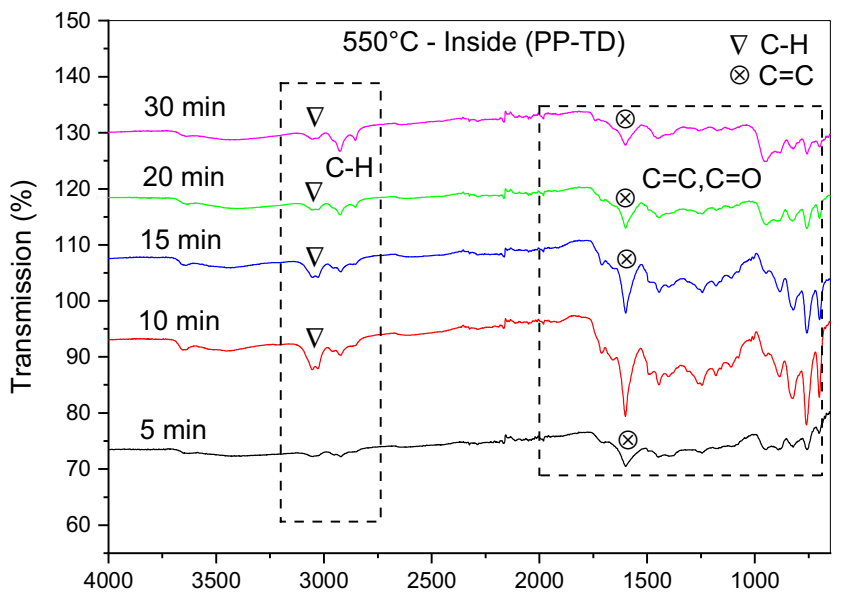

(d)

Wavenumber $\left(\mathrm{cm}^{-1}\right)$
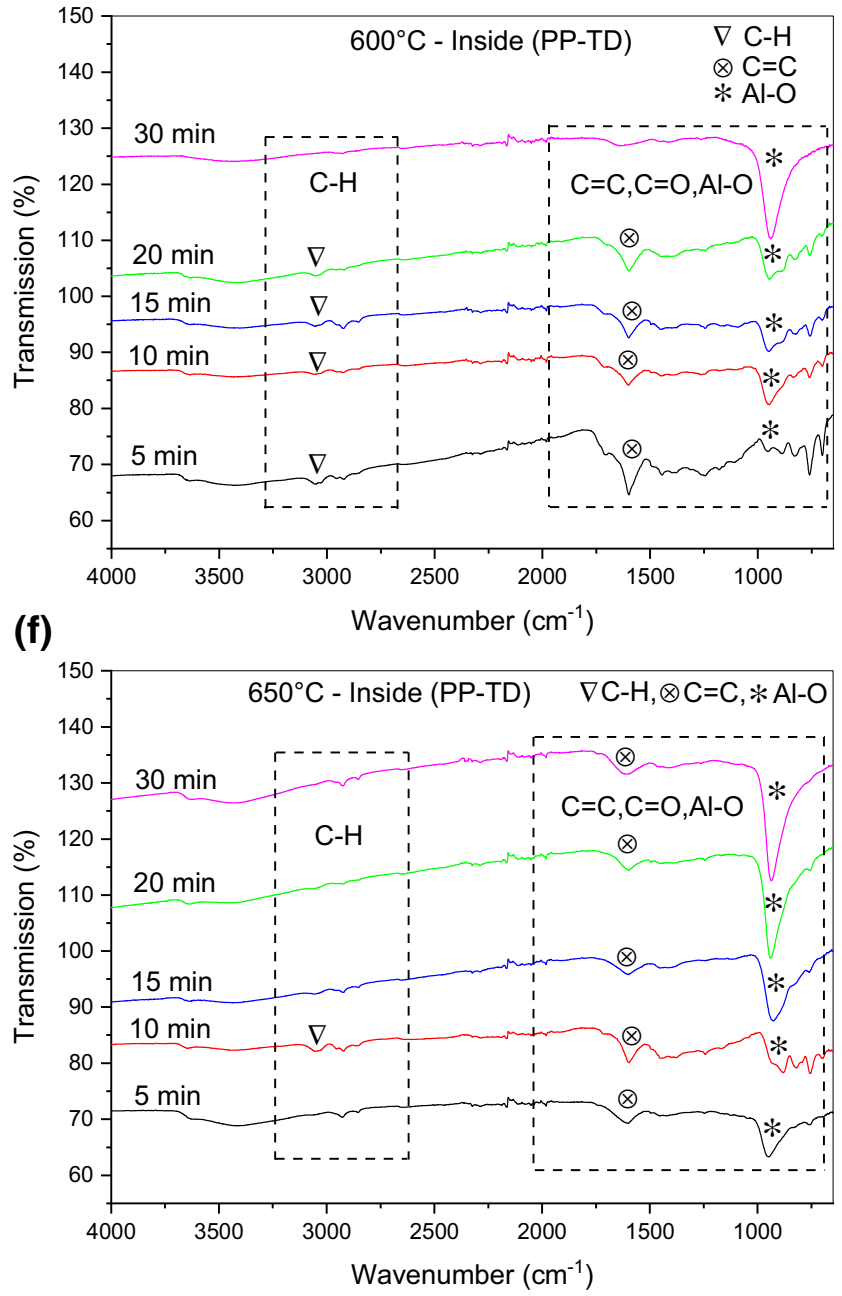

Fig. 9 FTIR of the outside (PET-TD) and inside (PP-TD) of the PLAP materials after TD in argon at $\mathbf{a}, \mathbf{b} 550^{\circ} \mathrm{C}, \mathbf{c}, \mathbf{d} 600^{\circ} \mathrm{C}$, and $\mathbf{e}, \mathbf{f} 650^{\circ} \mathrm{C}$

that the oxidation of the aluminum surface increases with the time of exposure to the environment during the TD; thus, the intensity of the $\mathrm{Al}_{2} \mathrm{O}_{3}$ peaks is prominent for the
XRD patterns of the sample 600T (30-min treatment in air) which can also be described by the measured phase quantities and elemental quantities by Rietveld fit. 


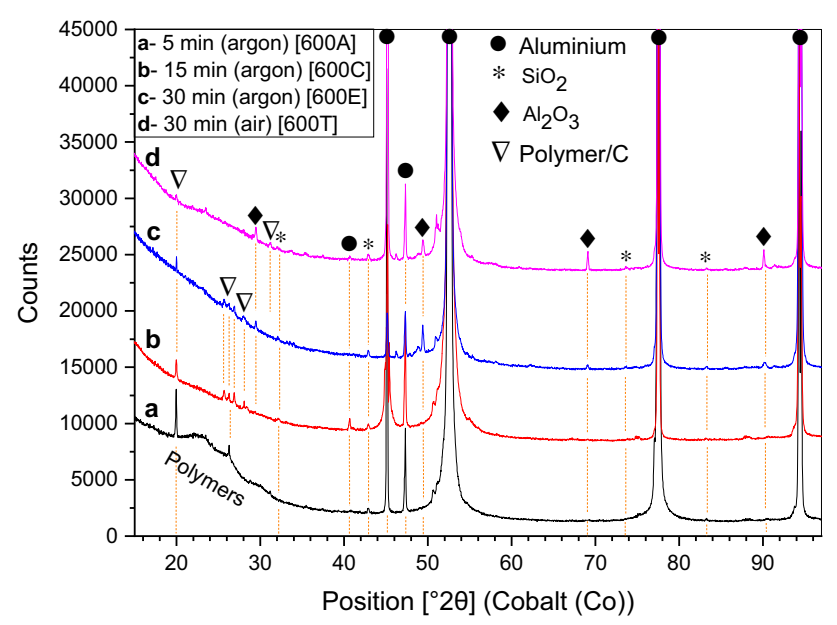

Fig. 10 XRD of the thermo-disengaged PLAP materials ( $a, b$, and $c)$ in argon and (d) in air

Table 3 represents the elemental quantifications estimated by the Rietveld fit for the samples $600 \mathrm{~A}, 600 \mathrm{C}$, $600 \mathrm{E}$, and $600 \mathrm{~T}$. The highest percentage of carbon/polymer phases (2.92) was estimated for the sample treated at $600^{\circ}$ for only $5 \mathrm{~min}$ which might be a close indication of the initial composition of the PLAP materials. From the elemental quantities, it can be noted that the percentages of aluminum for all the samples are about $96 \%$ and the other trace elements are silicon $(\mathrm{Si})$, carbon $(\mathrm{C})$, oxygen $(\mathrm{O})$, and hydrogen $(\mathrm{H})$. The weight percentage of oxygen was increased with the increase in thermal disengagement time where it is maximum for the treatment in air media. In contrast, the weight percentage of carbon was reduced with the exposure time and it is minimum in case of TD in air media due to the carbonization reaction of polymeric carbon with the atmospheric oxygen [23] which will predominantly produce carbon dioxide gas with an additional heat energy $(-393.5 \mathrm{~kJ} / \mathrm{mol})$ [69] which might increase the rate of combustion during the TD. This atmospheric oxygen can also react with hydrogen present in the polymers and produce water with an additional energy $(-190 \mathrm{~kJ} / \mathrm{mol})[23,69]$ which may cause the reduction in the existence of hydrogen from the surface of the aluminum which can be observed in Table 3 and also describable from the FTIR analysis represented in Fig. 9.

\subsubsection{X-ray photoelectron spectroscopy (XPS) analysis}

The XPS analysis of the PLAP materials after TD in inert and in an air atmosphere for a short time ( $5 \mathrm{~min}$ ) and a long time (30 $\mathrm{min}$ ) can be represented by Fig. 11. In overall, $\mathrm{Al} 2 \mathrm{p}, \mathrm{C} 1 \mathrm{~s}, \mathrm{O} 1 \mathrm{~s}$, and Si2p peaks were identified for all the spectrums and National Institute of Standards and Technology (NIST) database for XPS was utilized to find out the category of the components [70]. Figure $11 \mathrm{a}$, i represents the peaks for $\mathrm{Al} 2 \mathrm{p}$ for the thermo-disengaged samples in argon for 5 and $30 \mathrm{~min}$, respectively. The main spectrum can be deconvoluted into two major components (Al2pA at $73.6 \mathrm{eV}$ and Al2pB at $75.12 \mathrm{eV}$ for $600 \mathrm{~A}$ and $\mathrm{Al} 2 \mathrm{pA}$ at $73.76 \mathrm{eV}$ and $\mathrm{Al} 2 \mathrm{pB}$ at $75.55 \mathrm{eV}$ ) deduced from the metallic and oxide form of aluminum (Al2pA metallic, $\mathrm{Al} 2 \mathrm{pB}-\mathrm{Al}_{2} \mathrm{O}_{3}$ ) [71]. Polymer detachment and the form of the residual polymers can be explained by the peaks for $\mathrm{C} 1 \mathrm{~s}$ (Fig. 11b,c) which have segmented into four main components (C1sA, C1sB, C1sC, and C1sD). For 600A, it can be identified as the functional group $\mathrm{C}-\mathrm{C} / \mathrm{C}=\mathrm{C} / \mathrm{C} \equiv \mathrm{C}$ (at $284.8 \mathrm{eV}-\mathrm{C} 1 \mathrm{sA}),\left(-\mathrm{CH}_{2} \mathrm{CH}\left(\mathrm{CH}_{2} \mathrm{CH}_{3}\right)-\right)_{n}$ at $286.16 \mathrm{eV}(\mathrm{C} 1 \mathrm{sB})$, $\left(-\mathrm{C}-\mathrm{HCH}_{3}\right.$ partial unit) at $287.44 \mathrm{eV}(\mathrm{C} 1 \mathrm{sC})$, and $\left(-\mathrm{C}-\mathrm{HCH}_{3}\right.$ partial unit) at $288.44 \mathrm{eV}(\mathrm{C} 1 \mathrm{sD})$, and for 600P, the carbon-carbon groups and few more hydrocarbon groups can be observed at similar binding energies, where in the higher energy region, few $\mathrm{C}-\mathrm{OH}, \mathrm{C}-\mathrm{O}-\mathrm{C}, \mathrm{C}=\mathrm{O}$ groups can also be observed [72]. This result strongly supports the finding from the FTIR spectrums represented in Fig. 9 and the $\mathrm{X}$-ray diffraction analysis in Fig. 10. The existence of oxygen $\mathrm{O} 1 \mathrm{sA}, \mathrm{O} 1 \mathrm{sB}$ in the binding energy $531-533 \mathrm{eV}$ might be due to the minor oxidation of aluminum and the intrinsic oxygen present in the structure of PET polymer. Another trace element (silicon) present on the surface of the PLAP materials (confirmed by XRD and EDS mapping of the cross section) could be identified as Si2p for $600 \mathrm{~A}$ and Si2pA and Si2pB for 600E. In a close observation, it can be identified that the trace elements present
Table 3 Phases and elemental quantification by Rietveld fit

\begin{tabular}{|c|c|c|c|c|c|c|c|c|c|}
\hline \multicolumn{5}{|c|}{ Phase quantities } & \multicolumn{5}{|c|}{ Elemental quantities } \\
\hline Samples & $600 \mathrm{~A}$ & $600 C$ & $600 \mathrm{E}$ & $600 \mathrm{~T}$ & Samples & $600 \mathrm{~A}$ & $600 \mathrm{C}$ & $600 \mathrm{E}$ & $600 \mathrm{~T}$ \\
\hline Phases & Q. (\%) & Q. (\%) & Q. (\%) & Q. (\%) & Elements & Q. (\%) & Q. (\%) & Q. (\%) & Q. (\%) \\
\hline Al & 95.87 & 96.94 & 96.18 & 96.40 & $\mathrm{Al}$ & 96.43 & 96.89 & 96.82 & 96.48 \\
\hline $\mathrm{SiO}_{2}$ & 1.21 & 1.08 & 1.38 & 1.42 & $\mathrm{Si}$ & 0.56 & 0.50 & 0.64 & 0.90 \\
\hline $\mathrm{Al}_{2} \mathrm{O}_{3}$ & - & - & 0.90 & 1.43 & $\mathrm{O}$ & 0.65 & 0.58 & 0.76 & 1.42 \\
\hline \multirow[t]{2}{*}{ Polymer/C } & 2.92 & 1.98 & 1.54 & 0.75 & $\mathrm{C}$ & 2.05 & 1.96 & 1.69 & 1.12 \\
\hline & & & & & $\mathrm{H}$ & 0.31 & 0.07 & 0.09 & 0.08 \\
\hline Sum & 100 & 100 & 100 & 100 & Sum & 100 & 100 & 100 & 100 \\
\hline
\end{tabular}


(a) $\downarrow 600 \mathrm{~A}$ (5 min in argon) $\downarrow$ (e) $\downarrow$ 600P (5 min in air)

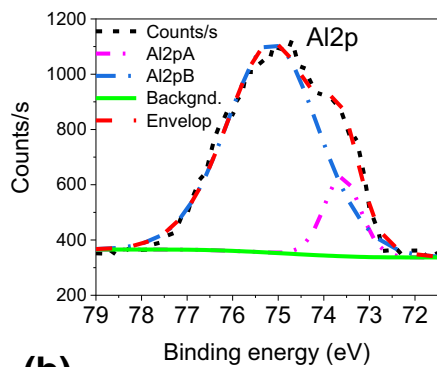

(b)
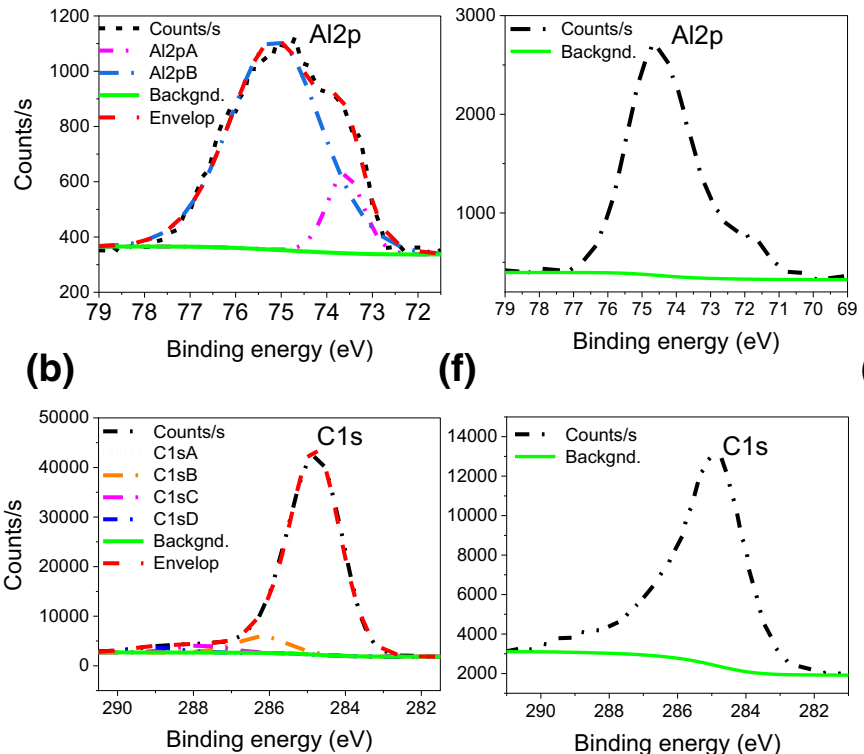

(c)

(g)

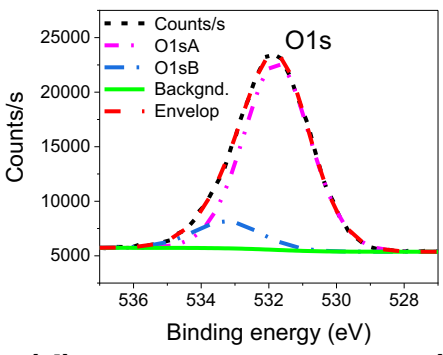

(d)

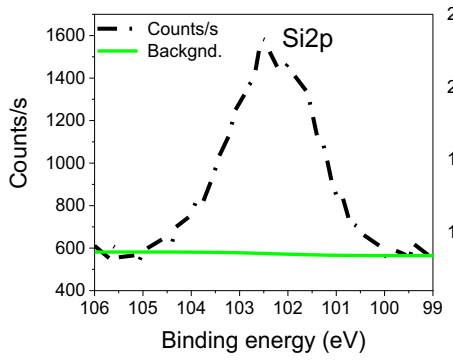

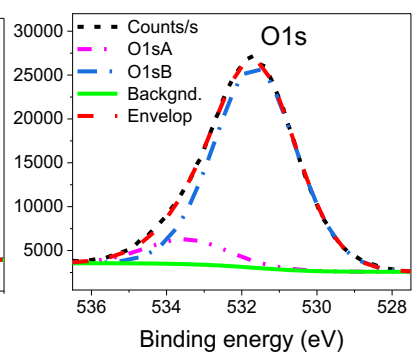

(h)

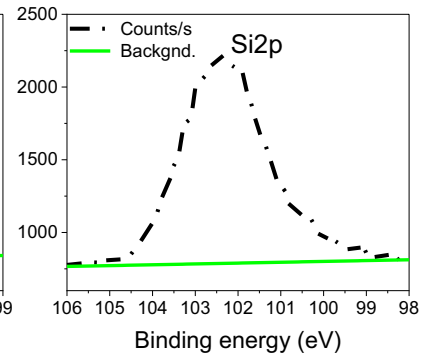

(i) $\downarrow 600 \mathrm{E}$ (30 min in argon) $\downarrow(\mathrm{m}) \downarrow$ 600T (30 min in air)

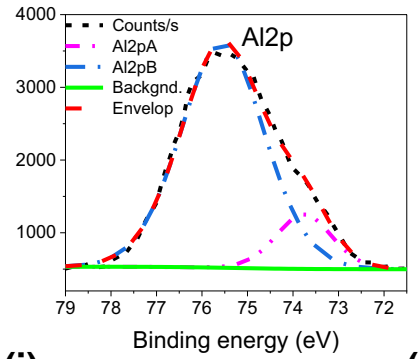

(j)

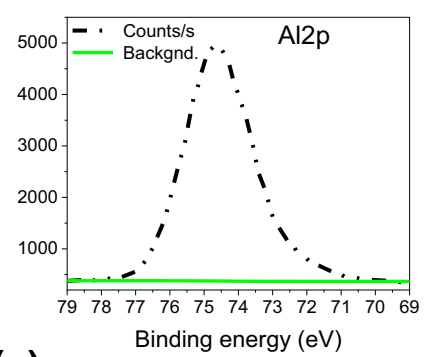

(n)
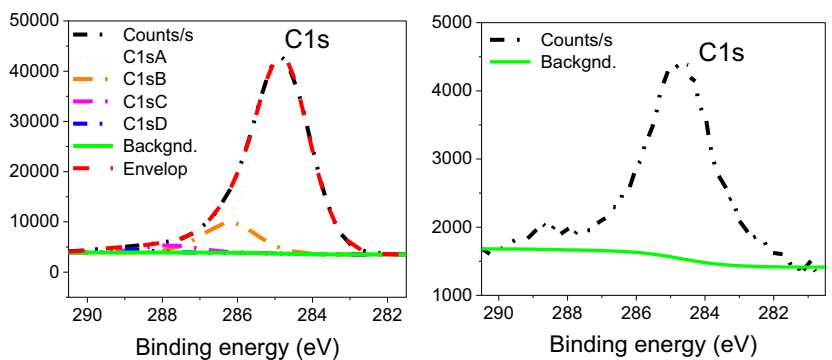

(o)

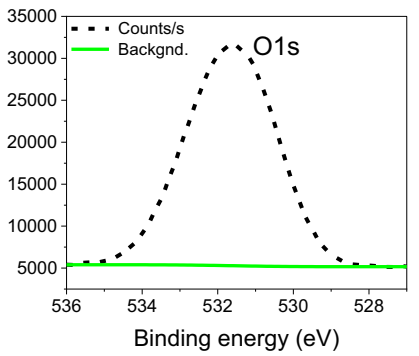

(I)

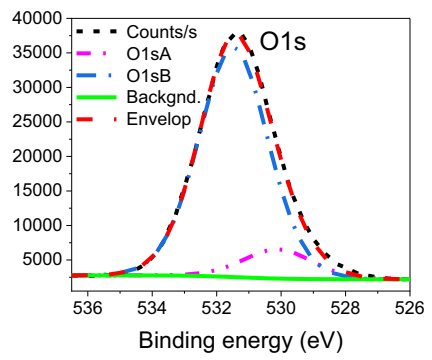

(p)

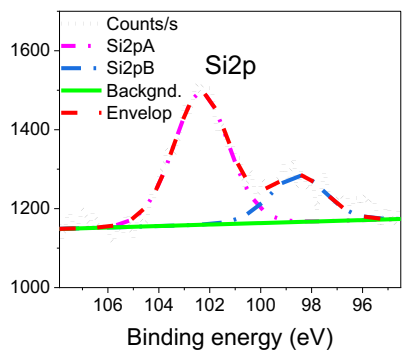

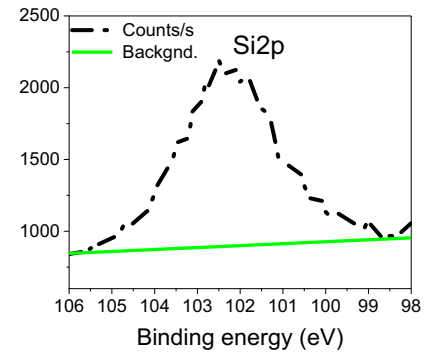

Fig. 11 XPS analysis of the PLAP materials after TD in argon and air atmosphere for 5 min and 30 min: a-d 5 min in argon-600A, e-h 5 min in air-600P, i-I $30 \mathrm{~min}$ in argon-600E, and $\mathbf{m}-\mathbf{p} 30 \mathrm{~min}$ in air-600T

at the binding energy $102.3 \mathrm{eV}(600 \mathrm{~A})$ are $\mathrm{SiO}_{1.02}$ where for $600 \mathrm{E}$ the identified elements can be marked as $\mathrm{SiO}$ (at $98.54 \mathrm{eV}-\mathrm{Si} 2 \mathrm{pB}$ ) and $\mathrm{SiO}_{1.19}$ (at $102.34 \mathrm{eV}-\mathrm{Si} 2 \mathrm{pA}$ ). The change in oxygen concentration in $\mathrm{Si}-\mathrm{O}_{\mathrm{x}}$ is due to the exposure time during the TD process [73]. Almost similar conclusions can be drawn for the other group of samples which is transformed in the air with a few exceptions of the rate of oxidation increased in this case. Therefore, no major deconvolution of the peaks was observed in this case of thermo-disengaged material. As the rate of oxidation was increased due to the presence of atmospheric air in the furnace chamber, the atomic percentage of carbon was reduced (due to carbonization reaction described earlier in Sect. 3.3) and the atomic percentage of oxygen was increased on the surface of aluminum in the form of aluminum oxide.

Table 4 is summary of the atomic percentages of the trace elements estimated by X-ray photoelectron spectroscopy (XPS). From the earlier description, the change in the atomic percentages of carbon and oxygen can be understood. The reason behind the rise in the atomic percentage of silicon is the increase in the oxygen concentration for 
Table 4 Elemental compositions estimated by XPS analysis

\begin{tabular}{lccccc}
\hline Elements (atom\%) & \multicolumn{2}{c}{ Media (argon) } & & \multicolumn{2}{c}{ Media (air) } \\
\cline { 2 - 3 } \cline { 6 - 7 } & $600 \mathrm{~A}$ & $600 \mathrm{E}$ & & $600 \mathrm{P}$ & $600 \mathrm{~T}$ \\
\hline Aluminum & 5.6 & 12.76 & & 16.88 & 31.95 \\
Carbon & 75.35 & 65.04 & & 40.38 & 10.66 \\
Oxygen & 16.83 & 21.16 & & 37.62 & 52.24 \\
Silicon & 2.22 & 1.04 & & 5.1 & 5.15 \\
\hline
\end{tabular}

the long-time exposure and TD in oxygen-rich environment which might expose the silicon layer observed on the aluminum surface with the oxygen to form silicon oxides. Easily oxidation behavior of aluminum always creates a very thin layer of $\mathrm{Al}_{2} \mathrm{O}_{3}$ on the surface of the aluminum which makes the percentage of aluminum atoms higher in the supplementary oxidation conditions $(600 \mathrm{E}$, $600 P$, and $600 T$ ). The X-ray of the XPS instrument can only penetrate 5-10 atomic layers [74] which can also be estimated as $\sim 1000 \AA(\sim 100 \mathrm{~nm})$ [75]. From the structure of the raw PLAP material, the polymer layers on both sides of aluminum were measured as $\sim 15 \mu \mathrm{m}$ (Fig. 2a) and the layers can exist with a thickness more than $2 \mu \mathrm{m}$ (Fig. 13d) after the TD. So, by XPS analysis the atomic percentage of aluminum only on the surface (in nanometer range) of the TD-treated PLAP materials can be estimated where the atomic percentage of aluminum in more than $100 \mu \mathrm{m}$ depth can be precisely estimated by XRD Rietveld analysis (shown in Table 3) because the penetration depth of the $\mathrm{X}$-ray for the X-ray diffractometer was more than $100 \mu \mathrm{m}$ (estimated by High Score Plus software).

\subsubsection{Elemental distribution on the aluminum surface after TD}

Figure 12 represents the elemental distribution on the surface of the PLAP materials after TD where Fig. 12a is the SE image of the surface after removal of the delaminated residues and other images describe the elemental distribution on the surface of the materials $(\sim 0.5-1 \mu \mathrm{m}$ depth at $5 \mathrm{kV})$. Due to the oxidation behavior of aluminum as described earlier, a prominent oxygen-rich region can be observed in the combined mapping (Fig. 12b) demonstrated by blue color. It means the oxidation was not uniform as it might be affected by the exposing conditions of the aluminum surface to the surrounding atmosphere. A major element was detected by the EDS spectra, and mapping is aluminum. Another two elements (carbon and oxygen) were present there on the surface in a noticeable amount. Though from the other analysis, the existence of silicon was observed, due to the lower spatial resolution of the
X-rays the element with lower weight percentages could not be detected and the quantitative information from this analysis might not be accurate enough. The EDS mapping and the quantitative details depend on the depth of penetration of the $X$-rays where the penetration depth of the $X$-rays unswervingly depends on the accelerating voltage and the density of the materials. It might be calculated by the following equation [76]:

$d=\frac{0.1 E^{1.5}}{\rho}$

where $d$ is the depth of penetration of the X-ray, $E$ is the accelerating voltage in $\mathrm{KV}$, and $\rho$ is the density of the materials in $\mathrm{g} / \mathrm{cm}^{3}$. If it is considered for aluminum, when the accelerating voltage was $5 \mathrm{kV}$, the depth of penetration is $0.42 \mu \mathrm{m}$.

\subsection{Cross section and the morphology of the coproducts after TD}

Figure 13a illustrates the cross section of the PLAP materials after $\operatorname{TD}\left(600^{\circ} \mathrm{C}, 15 \mathrm{~min}\right)$ where a layer of residues left on the surface of aluminum from the decomposition of polyethylene terephthalate (PET) is clearly visible. On the other side, where there was a polypropylene (PP) layer, no discernible residues can be observed which is in good agreement with the literature [52]. Complete decomposition of the PP polymer can be accomplished at $600{ }^{\circ} \mathrm{C}$ within 15 min of the treatment where PET might leave the residues at an even higher degree of TD parameters due to the tendency of the polymers having aromatic rings leave more residual components during thermal decomposition [67]. From the EDS analysis of the thermo-disengaged PET (PET-TD) side, a prominent peak for the carbon was detected (Fig. 13b) and only aluminum was detected in the middle part of the thermo-disengaged PLAP materials (Fig. 13c) as the oxidation can only happen on the outer surface of the aluminum. Figure 14a shows the microstructure of the cross section of the coffee pod after TD where it is clearly visible that the PET polymer leaves a thick layer of degraded residues on the Al surface and PP polymer seems to be devolatilized completely. More comprehensive image (taken by focus ion beam microscopy) of the cross section on PP side after TD represents a nanoscale oxidation formed on the Al surface, and there are still some carbon components upon the oxide layer (Fig. 14b). The thickness of the carbon layer is $85-90 \mathrm{~nm}$, and the thickness of the oxidized layer is $175-195 \mathrm{~nm}$. The elemental distribution of the cross section of the PLAP materials after TD is demonstrated in Fig. 14c-e. 

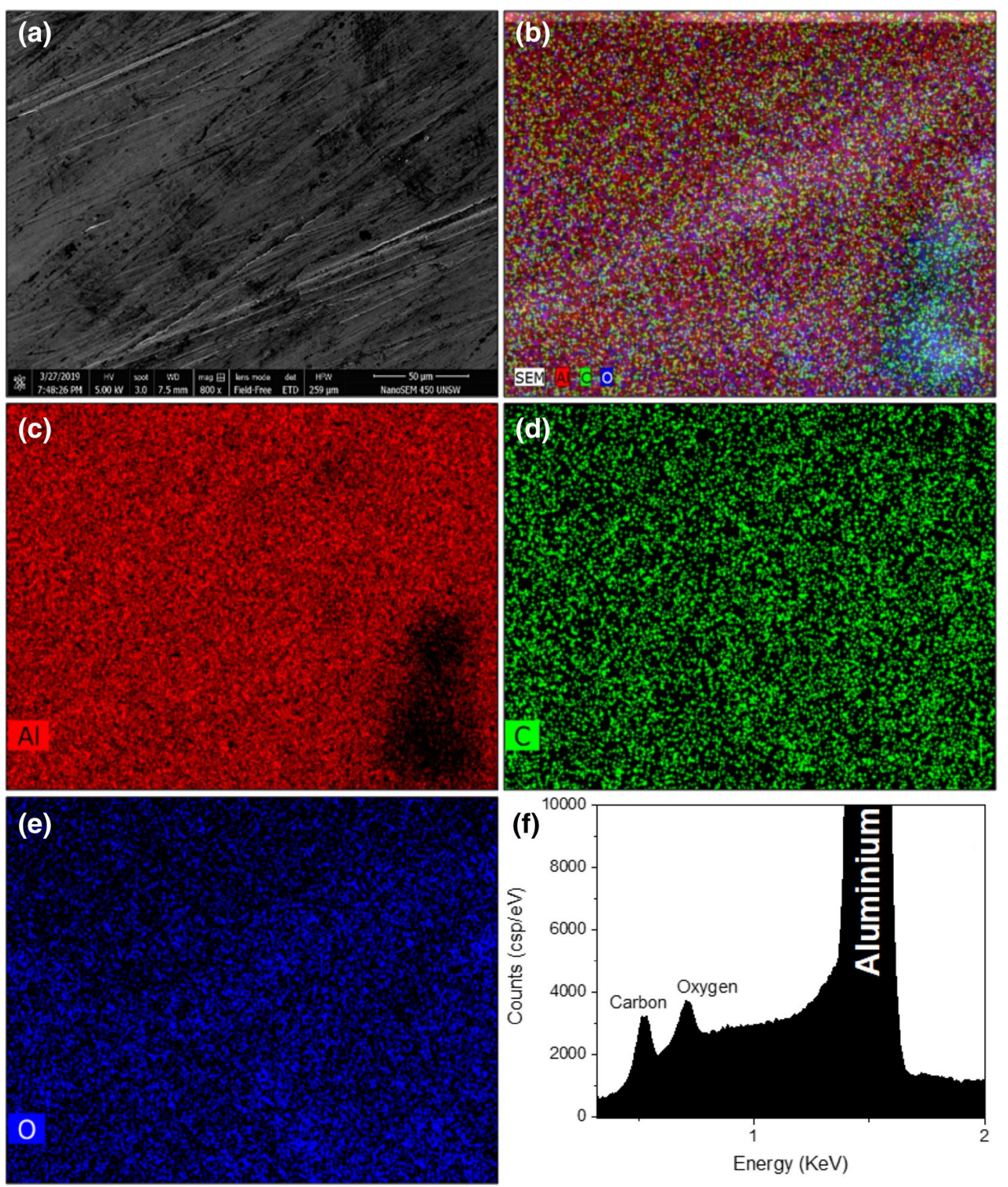

Fig. 12 Surface elemental distribution: a SE image of the surface of the PLAP materials after TD, $\mathbf{b}$ combined elemental mapping, $\mathbf{c}-\mathbf{e}$ individual elemental distribution, and $\mathbf{f}$ EDS spectra

Morphology of the residual particles is illustrated in Fig. 13d (magnified in Fig. 13e). From the EDS analysis (Fig. 13f), it is clear evidence that the residue contains mostly carbon particles with distinguishable sizes in the range of nano- to micrometers. As the structure of the PET and PP polymers in the studied materials consists of only carbon, hydrogen, and oxygen compounds, it is firmly supportive to find the carbon component in the residues from the cracking phenomena of the hydrocarbon chains [77].

\subsection{Composition of the recycled aluminum}

Two types of compounds were collected from the thermal disengagement of PLAP materials, aluminum, and carbon. The amount of carbon measured was about 3 wt\% by the LECO CS230 instrument, and the composition of the recycled aluminum was estimated by two different methods, inductively coupled plasma mass spectroscopy (ICP-MS) and laser-induced breakdown 


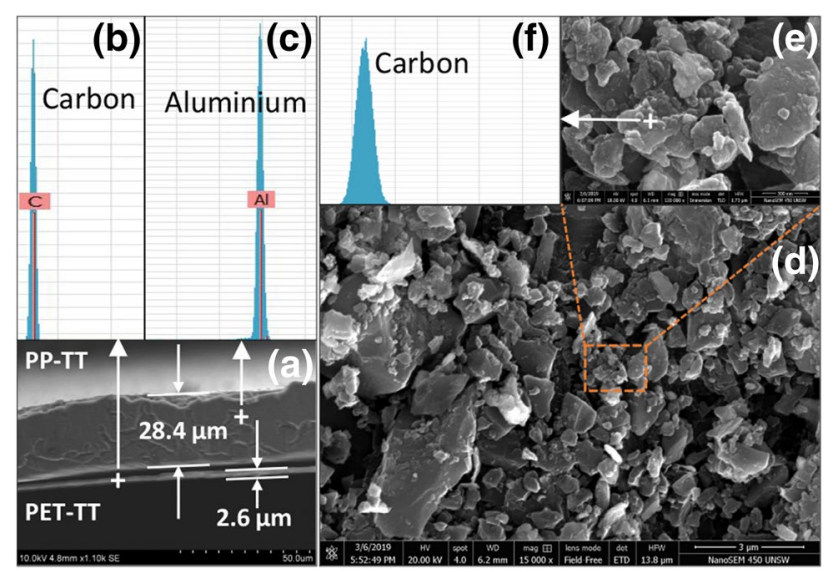

Fig. 13 a-c Cross section and EDS of the PLAP materials after TD d-f morphology and EDS of the residues after the thermal disengagement

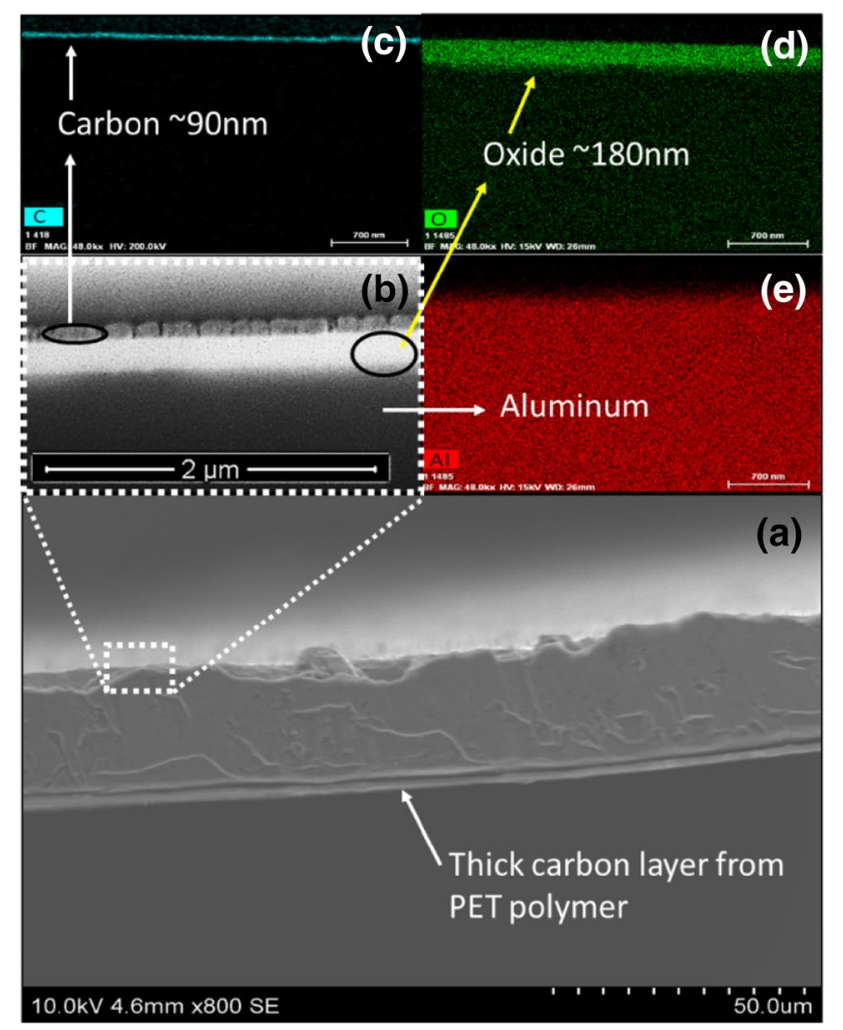

Fig. 14 a SEM of the cross section of the PLAP materials after TD, b TEM image of the cross section showing different layers existing after TD and c-e elemental distribution at the cross section

spectroscopy (LIBS). Table 5 summarizes the composition of the recycled aluminum where the purity of aluminum was found to be about $99 \%$ by both methods. It contains several impurities including silicon and iron in a noticeable amount. Silicon comes from the surface of the PLAP 
materials during the TD, and the iron might be present as an alloying element.

\section{Conclusions}

Polymer-laminated aluminum packaging (PLAP) materials were treated by TDT to recycle all the possible constituent elements to their original or in any other beneficial forms in a simple, sustainable, and innovative approach. The main conclusions of this study can be drawn as:

(a) Thin aluminum foil (thickness $\sim 30 \mu \mathrm{m}$ ) is laminated on both sides by two different types of polymers (PET and PP), and there is a silicon-rich layer at the interface between the metal and polymers. The weight percentages of aluminum and the polymers were $67.62 \%$ and $32.38 \%$ (PET $=30.27 \%$, and $P P=12.11 \%)$.

(b) To decompose the polymers from the surface of aluminum, TD at different temperatures $\left(400-650^{\circ} \mathrm{C}\right)$ for different treatment periods (5-30 min) was carried out in air and argon atmosphere. The optimum condition considering the maximum polymeric decomposition at lower energy consumption was $600^{\circ} \mathrm{C}$ (15 min). Increasing the treatment time could facilitate the process of the separation of residual materials from the surface of the aluminum.

(c) Different hydrocarbon gases, $\mathrm{CO}, \mathrm{CO}_{2}, \mathrm{H}_{2}, \mathrm{H}_{2} \mathrm{O}$, and few other gases were released during the TD process. Those gases carried out huge heat energy which could be utilized for other applications, and the hydrocarbon gases (especially aromatic hydrocarbons) can be further analyzed to reform into highenergy $\mathrm{CH}_{4}$ and $\mathrm{H}_{2}$ gases.

(d) Aluminum could be easily recycled in both ways by using or not using the inert gas into the furnace chamber. The main difference caused by the atmospheric air is the oxidation of aluminum surface up to $1.5 \%$ during the thermal disengagement process though minor oxidation is also unavoidable in case of the treatment in inert atmospheric condition.

(e) The derived coproduct from the decomposition of the polymers was carbon in the range of nano- to micrometers in size with a minor trace of oxides of aluminum and silicon. This carbon can be collected for other applications upon further processing.

This study offers an innovative, efficient, and sustainable microrecycling technique for a complex polymer-laminated metal packaging waste to transform into a clean and pure metal along with the source of value-added high-energy gaseous fuel and solid coproduct carbon in an excellent condition. This approach could protect the environment in an alternative and productive way and could be suggested as "One solution for several environmental problems."

Acknowledgements This research was supported by the Australian Research Council's Industrial Transformation Research Hub funding scheme (project: IH130200025). We gratefully acknowledge the technical support provided by Mark Wainwright Analytical Centre, UNSW, Sydney, Australia. We are also grateful to acknowledge Dr Irshad Mansuri, Dr Sagar Cholake, and Dr. Saroj Kumar Bhattacharyya.

Author's contribution Abdullah Al Mahmood performed all the experiments, analyzed the data and wrote the paper. Rumana Hossain designed the project and performed a microstructural analysis. Veena Sahajwalla supervised the study and gave suggestions to revise the manuscript. All authors analyzed data, discussed the results, read, edited and approved the manuscript.

\section{Compliance with ethical standards}

Conflict of interest The author(s) declare that they have no competing interests.

\section{References}

1. Kulkarni AK, Daneshvarhosseini S, Yoshida H (2011) Effective recovery of pure aluminum from waste composite laminates by sub-and super-critical water. J Supercrit Fluids 55:992-997

2. Australian Aluminium Council Ltd, Packaging (2019). http:// aluminium.org.au/aluminium/packaging/ Accessed 25 March 2019

3. International Aluminium Institute, Global Aluminium Recycling: A Cornerstone of Sustainable Development (2009). http://www. world-aluminium.org/media/filer_public/2013/01/15/fl000 0181.pdf

4. Forlin FJ, de Faria JAF (2002) Considerations about packing plastics recycling. Polímeros 12:1-10

5. Hernandez-Muñoz P, Catalá R, Gavara R (1999) Effect of sorbed oil on food aroma loss through packaging materials. J Agric Food Chem 47:4370-4374

6. Chytiri S, Goulas AE, Badeka A, Riganakos KA, Kontominas MG (2005) Volatile and non-volatile radiolysis products in irradiated multilayer coextruded food-packaging films containing a buried layer of recycled low-density polyethylene. Food Addit Contam 22:1264-1273

7. Badeka A, Goulas AE, Adamantiadi A, Kontominas MG (2003) Physicochemical and mechanical properties of experimental coextruded food-packaging films containing a buried layer of recycled low-density polyethylene. J Agric Food Chem 51:2426-2431

8. Singh B, Sharma N (2008) Mechanistic implications of plastic degradation. Polym Degrad Stab 93:561-584

9. Chytiri S, Goulas AE, Riganakos KA, Kontominas MG (2006) Thermal, mechanical and permeation properties of gammairradiated multilayer food packaging films containing a buried layer of recycled low-density polyethylene. Radiat Phys Chem 75:416-423

10. Siracusa V, Rocculi P, Romani S, Dalla Rosa M (2008) Biodegradable polymers for food packaging: a review. Trends Food Sci Technol 19:634-643 
11. Arena U, Di Gregorio F (2014) Gasification of a solid recovered fuel in a pilot scale fluidized bed reactor. Fuel 117:528-536

12. Vigano F, Consonni S, Grosso M, Rigamonti L (2010) Material and energy recovery from Automotive Shredded Residues (ASR) via sequential gasification and combustion. Waste Manag 30:145-153

13. Siddiqui MZ, Park Y-K, Kang Y, Watanabe A, Kim S, Kim Y-M (2019) Effective use of aluminum-plastic laminate as a feedstock for catalytic pyrolysis over micro and mesoporous catalysts. J Clean Prod 229:1093-1101. https://doi.org/10.1016/j.jclep ro.2019.04.404

14. Mancini SD, Zanin M (2002) Influence of reaction media in postconsumer pet hydrolysis. Polímeros 12:34-40

15. Viana ME, Riul A, Carvalho GM, Rubira AF, Muniz EC (2011) Chemical recycling of PET by catalyzed glycolysis: kinetics of the heterogeneous reaction. Chem Eng J 173:210-219

16. Goto M (2009) Chemical recycling of plastics using sub-and supercritical fluids. J Supercrit Fluids 47:500-507

17. Yang Y, Lu Y, Xiang H, Xu Y, Li Y (2002) Study on methanolytic depolymerization of PET with supercritical methanol for chemical recycling. Polym Degrad Stab 75:185-191

18. Yoshioka T, Sato T, Okuwaki A (1994) Hydrolysis of waste PET by sulfuric acid at $150 \mathrm{C}$ for a chemical recycling. J Appl Polym Sci 52:1353-1355

19. Roessler JG, Olivera FD, Wasman SJ, Townsend TG, McVay MC, Ferraro CC, Blaisi NI (2016) Construction material properties of slag from the high temperature arc gasification of municipal solid waste. Waste Manag 52:169-179

20. Haydary J, Susa D, Dudáš J (2013) Pyrolysis of aseptic packages (tetrapak) in a laboratory screw type reactor and secondary ther$\mathrm{mal} /$ catalytic tar decomposition. Waste Manag 33:1136-1141

21. Brems A, Dewil R, Baeyens J, Zhang R (2013) Gasification of plastic waste as waste-to-energy or waste-to-syngas recovery route. Nat Sci 5(6):695-704

22. Couto ND, Silva VB, Monteiro E, Rouboa A (2015) Assessment of municipal solid wastes gasification in a semi-industrial gasifier using syngas quality indices. Energy 93:864-873

23. Calder GV, Stark TD (2010) Aluminum reactions and problems in municipal solid waste landfills. Pract Period Hazard Toxic Radioact Waste Manag 14:258-265

24. López FA, Román CP, García-Díaz I, Alguacil FJ (2015) Oxidation and waste-to-energy output of aluminium waste packaging during incineration: a laboratory study. Waste Manag 43:162-167

25. Padden FJ Jr, Keith HD (1959) Spherulitic crystallization in polypropylene. J Appl Phys 30:1479-1484

26. Mehta AK, Chen MC (1994) Heat sealable blend of very low density polyethylene or plastomer with polypropylene based polymers and heat sealable film and articles made thereof. U.S. Patent No. 5,358,792. Washington, DC: U.S. Patent and Trademark Office

27. Cheremisinoff NP (2001) PET (POLYETHYLENE TEREPHTALATE). In: N.P.B.T.-C.E. of P.E.T. Cheremisinoff (ed) Butterworth-Heinemann, Boston, pp 200-255. https://doi.org/10.1016/B978-0-08050282-3.50021-4

28. Qin H, Zhang S, Zhao C, Feng M, Yang M, Shu Z, Yang S (2004) Thermal stability and flammability of polypropylene/montmorilIonite composites. Polym Degrad Stab 85:807-813. https://doi. org/10.1016/j.polymdegradstab.2004.03.014

29. Rodríguez-Llamazares S (2013) Polypropylene/starch blends: study of thermal and morphological properties. J Chil Chem Soc 58:1643-1646

30. Shah J, Jan MR (2015) Effect of polyethylene terephthalate on the catalytic pyrolysis of polystyrene: investigation of the liquid products. J Taiwan Inst Chem Eng 51:96-102
31. Girija BG, Sailaja RRN, Madras G (2005) Thermal degradation and mechanical properties of PET blends. Polym Degrad Stab 90:147-153. https://doi.org/10.1016/j.polymdegradstab .2005.03.003

32. Wendlandt WW (1986) The development of thermal analysis instrumentation 1955-1985. Thermochim Acta 100:1-22

33. Coats AW, Redfern JP (1964) Kinetic parameters from thermogravimetric data. Nature 201:68

34. White JE, Catallo WJ, Legendre BL (2011) Biomass pyrolysis kinetics: a comparative critical review with relevant agricultural residue case studies. J Anal Appl Pyrolysis 91:1-33

35. Mayyas M, Mayyas M, Pahlevani F, Liu Z, Rajarao R, Sahajwalla $V$ (2016) From automotive shredder residue to nano-ceramics and graphitic carbon-thermal degradation kinetics. J Anal Appl Pyrolysis 120:60-74

36. Koga N (1994) A review of the mutual dependence of Arrhenius parameters evaluated by the thermoanalytical study of solidstate reactions: the kinetic compensation effect. Thermochim Acta 244:1-20

37. Encinar JM, González JF (2008) Pyrolysis of synthetic polymers and plastic wastes. Kinetic study. Fuel Process Technol 89:678-686

38. Liu Z, Wang Q, Zou Z, Tan G (2011) Arrhenius parameters determination in non-isothermal conditions for the uncatalyzed gasification of carbon by carbon dioxide. Thermochim Acta 512:1-4

39. Salema AA, Afzal MT, Motasemi F (2014) Is there synergy between carbonaceous material and biomass during conventional pyrolysis? A TG-FTIR approach. J Anal Appl Pyrolysis 105:217-226

40. Droussi Z, D'orazio V, Provenzano MR, Hafidi M, Ouatmane A (2009) Study of the biodegradation and transformation of olivemill residues during composting using FTIR spectroscopy and differential scanning calorimetry. J Hazard Mater 164:1281-1285

41. Yang J, Chen H, Zhao W, Zhou J (2016) TG-FTIR-MS study of pyrolysis products evolving from peat. J Anal Appl Pyrolysis 117:296-309

42. Wu X, Wu Y, Wu K, Chen $Y$, Hu H, Yang M (2015) Study on pyrolytic kinetics and behavior: the co-pyrolysis of microalgae and polypropylene. Bioresour Technol 192:522-528. https://doi. org/10.1016/j.biortech.2015.06.029

43. Dang $X$, Wang $Y$, Hu C, Huang J, Chen H, Wang S, Hu S (2014) Preparation and application of a novel electrochemical sensing material based on surface chemistry of polyhydroquinone. Mater Sci Eng C 40:9-15. https://doi.org/10.1016/j. msec.2014.03.039

44. Aroca R, Thedchanamoorthy A (1995) Vibrational studies of molecular organization in evaporated phthalocyanine thin solid films. Chem Mater 7:69-74. https://doi.org/10.1021/cm000 49a012

45. Chiem LT, Huynh L, Ralston J, Beattie DA (2006) An in situ ATRFTIR study of polyacrylamide adsorption at the talc surface. J Colloid Interface Sci 297:54-61. https://doi.org/10.1016/j. jcis.2005.10.037

46. He P, Xiao Y, Zhang P, Xing C, Zhu N, Zhu X, Yan D (2005) Thermal degradation of syndiotactic polypropylene and the influence of stereoregularity on the thermal degradation behaviour by in situ FTIR spectroscopy. Polym Degrad Stab 88:473-479. https ://doi.org/10.1016/j.polymdegradstab.2004.12.008

47. Jin W, Shen D, Liu Q, Xiao R (2016) Evaluation of the co-pyrolysis of lignin with plastic polymers by TG-FTIR and Py-GC/MS. Polym Degrad Stab 133:65-74. https://doi.org/10.1016/j.polymdegra dstab.2016.08.001

48. Das P, Tiwari P (2018) Valorization of packaging plastic waste by slow pyrolysis. Resour Conserv Recycl 128:69-77 
49. Martín-Gullón I, Esperanza M, Font R (2001) Kinetic model for the pyrolysis and combustion of poly-(ethylene terephthalate) (PET). J Anal Appl Pyrolysis 58-59:635-650. https://doi. org/10.1016/S0165-2370(00)00141-8

50. FakhrHoseini SM, Dastanian M (2013) Pyrolysis of LDPE, PP and PET plastic wastes at different conditions and prediction of products using NRTL activity coefficient model. Arab J Chem. https://doi.org/10.1155/2013/487676

51. Rabek JF (1975) Chapter 4 oxidative degradation of polymers. In: Bamford CH, Tipper CFHBT-CCK (eds) Degradation of polymers. Elsevier, Amsterdam, pp 425-538. https://doi.org/10.1016/ S0069-8040(08)70336-4

52. Polymer properties database, THERMAL-OXIDATIVE DEGRADATION OF POLYMERS (2015). https://polymerdatabase.com/ polymerchemistry/ThermalDegradation.html Accessed 15 April 2019

53. Jellinek HHG (1977) Aspects of degradation and stabilization of polymers. Elsevier Scientific Pub. Co., Amsterdam

54. Sovová K, Ferus M, Matulková I, Španěl P, Dryahina K, Dvořák O, Civiš S (2008) A study of thermal decomposition and combustion products of disposable polyethylene terephthalate (PET) plastic using high resolution fourier transform infrared spectroscopy, selected ion flow tube mass spectrometry and gas chromatography mass spectrometry. Mol Phys 106:1205-1214. https://doi.org/10.1080/00268970802077876

55. Lu C-H, Chiang K-Y (2017) Gasification of non-recycled plastic packaging material containing aluminum: hydrogen energy production and aluminum recovery. Int J Hydrog Energy 42:27532-27542. https://doi.org/10.1016/j.ijhydene.2017.09.041

56. Martínez-Lera S, Ranz JP (2017) On the development of a polyolefin gasification modelling approach. Fuel 197:518-527. https ://doi.org/10.1016/j.fuel.2017.02.032

57. Mayyas M, Pahlevani F, Handoko W, Sahajwalla V (2016) Preliminary investigation on the thermal conversion of automotive shredder residue into value-added products: graphitic carbon and nano-ceramics. Waste Manag 50:173-183. https://doi. org/10.1016/j.wasman.2016.02.003

58. Mohsen Soltani E, Ghorannevis Z, Shirazi M (2013) Effect of $\mathrm{Ar} / \mathrm{CH}_{4}$ mixture ratio on properties of $\mathrm{Ag} / \mathrm{C}: \mathrm{H}$ nanocomposite prepared by DC sputtering. Adv Mater Sci Eng. https://doi. org/10.1155/2013/142450

59. Gökağaç G, Sonsuz M, Şen F, Kısakürek D (2006) Atom transfer rearrangement radical polymerization of diamminebis $(2$, 4, 6-trihalophenolato) copper (II) complexes in the solid state. Zeitschrift Für Naturforsch B 61(10):1222-1228

60. I.S.A.W. Committee (1991) An infrared spectroscopy atlas for the coatings industry. Fed Soc Coat Technol

61. Goldstein DN, McCormick JA, George SM (2008) $\mathrm{Al}_{2} \mathrm{O}_{3}$ atomic layer deposition with trimethylaluminum and ozone studied by in situ transmission FTIR spectroscopy and quadrupole mass spectrometry. J Phys Chem C 112(49):19530-19539

62. Öhman M, Persson D, Leygraf C (2006) In situ ATR-FTIR studies of the aluminium/polymer interface upon exposure to water and electrolyte. Prog Org Coat 57:78-88
63. Daffalla SB, Mukhtar H, Shaharun MS (2010) Characterization of adsorbent developed from rice husk: effect of surface functional group on phenol adsorption. J Appl Sci 10:1060-1067

64. Agrawal S, Ingle N, Maity U, Jasra RV, Munshi P (2018) Effect of aqueous $\mathrm{HCl}$ with dissolved chlorine on certain corrosionresistant polymers. ACS Omega 3:6692-6702

65. Motsa MM, Msagati TAM, Thwala JM, Mamba BB (2015) Polypropylene-zeolite polymer composites for water purification: synthesis, characterisation and application, Desalin. Water Treat 53:2604-2612

66. Kumar U, Gaikwad V, Sahajwalla V (2018) Transformation of waste toner to iron using E-waste plastics as a carbon resource. J Clean Prod 192:244-251. https://doi.org/10.1016/j.jclep ro.2018.05.010

67. Yin S, Rajarao R, Sahajwalla V (2019) Thermal transformation of metallized plastic packaging waste into value-added al/al 3 c 4/ aln resources. ACS Sustain Chem Eng 7:1723-1733. https://doi. org/10.1021/acssuschemeng.8b05503

68. Yin S, Rajarao R, Gong B, Wang Y, Kong C, Sahajwalla V (2019) Thermo-delamination of metallised composite plastic: an innovative approach to generate Aluminium from packaging plastic waste. J Clean Prod 211:321-329. https://doi.org/10.1016/j.jclep ro.2018.11.158

69. David RL (2003) Handbook of chemistry and physics. Natl Inst Stand. Technol

70. Naumkin AV, Kraut-Vass A, Gaarenstroom SW, Powell CJ (2012) NIST X-ray photoelectron spectroscopy database, version 4.1. Natl Inst Stand Technol Gaithersbg. https://doi.org/10.18434/ T4T88K

71. Cordier F, Ollivier E (1995) X-ray photoelectron spectroscopy study of aluminium surfaces prepared by anodizing processes. Surf Interface Anal 23(9):601-608

72. De Giglio E, Ditaranto N, Sabbatini L (1993) 3 polymer surface chemistry: characterization by XPS. Chemistry (Easton) 4(n.d.):6

73. Alfonsetti R, Lozzi L, Passacantando M, Picozzi P, Santucci S (1993) XPS studies on SiOx thin films. Appl Surf Sci 70:222-225

74. Dr Bill Gong Surface analysis. Surf Anal Lab Mark Wainwright Anal Centre, UNSW, Sydney. (n.d.). https://www.analytical.unsw. edu.au/facilities/sseau/salab Accessed 29 April 2019

75. Kawai J, Adachi H, Kitajima Y, Maeda K, Hayakawa S, Gohshi Y (1997) Inelastic mean free path of photoelectrons in Ag determined by total reflection X-ray photoelectron spectroscopy. Anal Sci 13(5):797-801

76. PJ Potts (1987) Electron probe microanalysis BT-a handbook of silicate rock analysis. In: Potts PJ (ed) Springer, Dordrecht, $p$ 336. https://doi.org/10.1007/978-94-015-3988-3_10

77. Tuffi R, Abramo SD, Cafiero LM, Trinca E, Ciprioti SV (2018) Thermal behavior and pyrolytic degradation kinetics of polymeric mixtures from waste packaging plastics. Express Polym Lett 12:82-99. https://doi.org/10.3144/expresspolymlett.2018.7

Publisher's Note Springer Nature remains neutral with regard to jurisdictional claims in published maps and institutional affiliations. 